\title{
A influência de fatores demográficos e estruturais nos significados do trabalho entre brasileiros: evidências do World Values Survey
}

\author{
Cibele Satuf ${ }^{1}$ (D) \\ Jorge Alexandre Barbosa Neves ${ }^{2}$ (i)
}

\begin{abstract}
O trabalho passou por transformações que modificaram os valores e determinantes de seus significados, colocando em xeque sua centralidade. Este artigo investiga os significados do trabalho entre brasileiros, bem como a influência de elementos demográficos e estruturais nessa atribuição. Os significados do trabalho referem-se à interpretação individual, influenciada pelo contexto social, do trabalho e do que ele representa. Utilizou-se a amostra brasileira do World Values Survey. A influência de características socioeconômicas e estruturais foi analisada via modelagens de equações estruturais (MEE). $O$ modelo foi bem ajustado, tendo um coeficiente de determinação de 0,951 . Os resultados descritivos indicaram alta valorização do trabalho e forte percepção deste como obrigação social. Os resultados da MEE indicaram que homens atribuem maior significado ao trabalho em comparação com mulheres e que o aumento da idade influencia a atribuição de significados do trabalho. A criatividade, a intelectualidade e a independência nas atividades executadas têm influência indireta (via nível socioeconômico - NSE) e negativa na percepção de significados do trabalho. As análises priorizaram a articulação entre aspectos sociais e econômicos com o processo de significação do trabalho, perspectiva pouco explorada na produção científica brasileira, mas fundamental para que o fenômeno seja compreendido de maneira mais ampla, especialmente em sociedades estratificadas, como o Brasil.
\end{abstract}

Palavras-chave: significados do trabalho; brasileiros; fatores de influência; World Values Survey

\section{Introdução}

O trabalho passou por diversas transformações ao longo do tempo. As mudanças em sua estruturação no decorrer do desenvolvimento da sociedade contribuíram para moldar os significados que Ihe são atribuídos. Em sociedades mais antigas, como na Antiguidade Clássica e na Renascença, o trabalho era visto como uma atividade de baixa

\footnotetext{
1 Universidade Federal de Minas Gerais, Faculdade de Filosofia e Ciências Humanas. Belo Horizonte (MG), Brasil. E-mail: <cibelesatuf@gmail.com>.

2 Universidade Federal de Minas Gerais, Faculdade de Filosofia e Ciências Humanas. Belo Horizonte (MG), Brasil. E-mail: <jorgeaneves@gmail.com>.
} 
importância, à margem de valores sociais centrais. Com o desenvolvimento da sociedade industrial, a atividade passa a ser alvo de algum reconhecimento em termos de valores políticos, psicológicos e sociais, chegando a ocupar um lugar de maior importância e centralidade na vida dos indivíduos. Contudo, as transformações no mundo do trabalho culminaram em um período marcado pela flexibilidade e imaterialidade, o que coloca em xeque a centralidade do trabalho. Tem-se, portanto, um cenário marcado por transformações que alteram a concepção social, os valores, as atitudes e determinantes dos sentidos e os significados do trabalho (Araújo e Sachuk, 2007).

As alterações relacionadas à estruturação do trabalho ajudaram a moldar os seus significados ao longo do tempo e fundamentaram um extenso debate. Por um lado, há teses que advogam o fim de sua importância e centralidade, defendidas por autores como Méda (2010) e Gorz (1982). Segundo essa abordagem, a realidade atual, marcada por forte desemprego e precarização do trabalho, traz impactos sociais profundos, já que a ausência de um trabalho significativo se traduz em fonte de miséria e frustração (Dahrendorf, 1980). Esse cenário desfavorável contribui para a queda da centralidade do trabalho e valorização de outras esferas sociais (Offe, 1989). Por outro lado, autores como Castel (1997) e Antunes (2009) defendem a importância do trabalho para a estrutura social, mesmo em situações de degradação e precarização. Ainda que diante de uma nova morfologia, marcada por formas de estranhamento e alienação, o trabalho se mantém como uma referência nas esferas psicológica, social e econômica (Navarro e Padilha, 2007). Nessa direção, De la Garza e Hernández (2000) afirmam que as teses sobre o fim do trabalho se fundamentaram em teorias direcionadas a contextos e temporalidades específicos, como aqueles vivenciados em alguns países europeus avançados e nos Estados Unidos, marcados pela concretização de políticas neoliberais e pelo declínio da força sindical. Os autores esclarecem que os defensores da tese do fim do trabalho, ao atestarem que as mudanças nas posições e relações de mercado influenciariam na determinação de normas, valores e atitudes, estariam adotando uma análise de caráter amplamente estruturalista e simplista. Nesse sentido, De la Garza e Hernández (2000) defendem que as relações entre estruturas, ocupações, subjetividades e ações coletivas são demasiado complexas, não cabendo a adoção de tamanho situacionismo estruturalista. Por mais que o trabalho seja permeado por ambiguidades que perpassam desde a sua percepção como fonte de criação e de subsistência à sua identificação como fonte de desenvolvimento, satisfação e identidade (Kovács, 2006), a categoria trabalho mantém, sem dúvidas, sua importância social. Portanto, não se pode falar de um fim da sociedade do trabalho, sendo inconteste a sua relevância social (Bizerra e Souza, 2014).

Mesmo diante dessas transformações, a sociedade permanece se guiando em prol da acumulação de capital, e, nesse movimento, o trabalho permanece como principal mercadoria e mecanismo de geração de valor. Essa realidade é ainda mais patente quando se analisam países latino-americanos, nos quais a atividade persiste como um elemento de formação e manutenção do ser social. Nessas realidades, o acesso restrito ao consumo 
se faz presente, algo que tende a ser superado essencialmente por meio do trabalho, o que reforça sua manutenção como um fator de integração social e garantia da sobrevivência (Oliveira e Piccinini, 2011). Nesse sentido, não se pode falar no fim de sua posição de centralidade no entendimento social (Cardoso, 2008).

Nessa investigação, assume-se que o trabalho permanece como um elemento central para a sociedade. Contudo, entende-se que as mudanças que ocorreram em seus processos e estrutura possuem potencial para influenciar a conformação dos significados a ele atribuídos, bem como a percepção de sua importância na sociedade. Desse modo, pretende-se investigar os significados atribuídos ao trabalho por brasileiros, e também a influência de elementos demográficos e estruturais nessa atribuição.

Os significados do trabalho são abordados em diversos estudos. Na produção científica brasileira, geralmente são analisados com enfoque em categorias ocupacionais, como entre professores universitários (Vilas Boas e Morin, 2014, 2015), enfermeiros (Rodrigues, Barrichello e Morin, 2016), agentes penitenciários (Santos, 2014), executivos (Coda e Fonseca, 2004) ou entre trabalhadores ligados a instituições específicas (Bitencourt et al., 2014). Essas perspectivas consideram que o processo de atribuição de significados do trabalho ocorre essencialmente entre pessoas que realizam atividades laborais, diferenciando-se conforme a área de atuação dos indivíduos. Ainda que alguns desses estudos englobem de alguma maneira a dimensão social, os métodos empíricos que os fundamentam impedem que os resultados sejam generalizados.

Ao efetuarem uma extensa revisão de literatura sobre os significados do trabalho, Rosso, Dekas e Wrzesniewski (2010) chamaram atenção para o fato de que as investigações tendem, em linhas gerais, a analisar fatores ou processos singulares que contribuem para o significado do trabalho, em vez de adotarem uma visão mais abrangente. Ardichvili e Kuchinke (2009) destacam a importância da articulação entre aspectos sociais e econômicos com o processo de significação do trabalho, especialmente em sociedades estratificadas, como no caso do Brasil, para que o fenômeno possa ser compreendido de maneira mais ampla.

Desse modo, este artigo pretende contribuir para a literatura científica ao incluir elementos sociais mais amplos na atribuição dos significados do trabalho. Partindo de uma amostra representativa da população brasileira, o objetivo geral dessa investigação é verificar a influência de características socioeconômicas e estruturais na atribuição dos significados do trabalho. Como desdobramento do objetivo geral, têm-se como objetivos específicos: identificar os significados atribuídos ao trabalho; verificar em que medida características demográficas, como idade, sexo e religião, influenciam na diferenciação dos significados que são atribuídos ao trabalho; e analisar a influência de características estruturais, como a natureza da atividade realizada e o nível socioeconômico, na atribuição dos significados do trabalho.

O artigo está organizado em quatro seções, além desta primeira, de caráter introdutório. Na "Fundamentação teórica", a conceituação sobre os significados do trabalho 
é apresentada, indicando alguns de seus estudos seminais, bem como a proposta debatida pelo Meaning of Work Research Team (MOW, 1987), adotada como referência neste artigo. Em seguida, a "Metodologia" permite conhecer a base de dados secundária utilizada, desenvolvida pelo World Values Survey, as "Hipóteses" a serem testadas, assim como as "Análises estatísticas" empregadas na investigação. Os achados da pesquisa são discutidos na seção "Resultados" e, finalmente, a seção "Conclusões" contempla alguns apontamentos sobre esses achados, assim como algumas limitações da pesquisa e indicações de investigações futuras.

\section{Fundamentação teórica}

\section{Os significados do trabalho}

Os significados do trabalho são analisados através de diversas abordagens teóricas (Rodrigues et al., 2018; Rosso, Dekas e Wrzesniewski, 2010), tendo suas origens nos campos da psicologia e da sociologia. A perspectiva psicológica afirma que as percepções sobre os significados do trabalho se fundamentam nas interpretações subjetivas que os indivíduos fazem sobre suas experiências e interações no decorrer dessa atividade, conforme seu referencial próprio. Já a vertente sociológica pressupõe que a avaliação desses significados sofre influência de visões de mundo e sistemas de valores sociais ou culturais, sendo, portanto, mais complexa. A atribuição de significados leva em conta não somente as atitudes e expectativas em relação ao trabalho, mas também o papel dessa categoria na sociedade, bem como as inter-relações entre a atividade e outras esferas significativas (Méda e Vendramin, 2013; Warr, 2008). Portanto, quando os sistemas sociais e culturais em torno das pessoas atribuírem valor às suas atividades laborais, o trabalho, possivelmente, será considerado significativo.

O processo de avaliação do trabalho compreende um conjunto flexível de cognições que se desenvolvem tanto antes quanto no decorrer do processo de socialização no trabalho, sendo influenciado por fatores contextuais, sociais e experiências pessoais (Zubieta et al., 2008). Os significados do trabalho abrangem um componente da realidade socialmente construída e reproduzida, que resulta do intercâmbio entre variáveis pessoais e sociais em um determinado contexto histórico (Tolfo e Piccinini, 2007), com implicações que vão desde ações individuais até processos grupais e sociais (Tolfo et al., 2011). Em sua formação, há um conteúdo que é partilhado socialmente, mas que, ao mesmo tempo, é permeado por singularidades que se formam nas trajetórias individuais e sociais. Incorporam, portanto, elementos ideológicos da sociedade, relacionados à estrutura macroeconômica e influenciados por agentes de socialização (Borges e Barros, 2015).

Esses significados se relacionam à cognição social e neles se articulam as dimensões individual (história pessoal), social e ocupacional. Referem-se à interpretação individual, embora amplamente influenciada pelo contexto social, do trabalho e do que ele 
representa para o indivíduo, sendo que, para uns, pode ser meio de sustento, para outros, uma vocação ou até mesmo um meio de se manter ocupado (Rosso, Dekas e Wrzesniewski, 2010). Goulart (2009) salienta que o significado do trabalho pode ser compreendido como um conjunto de valores, crenças e atitudes em relação ao trabalho, permeado por variações subjetivas no âmbito da organização e do emprego. Constitui-se, portanto, como uma cognição subjetiva histórica e em mudança contínua.

Um dos estudos seminais acerca dos significados do trabalho foi conduzido por Morse e Weiss (1955). Os autores estavam interessados em analisar o impacto das mudanças ocasionadas pela industrialização nos significados atribuídos ao trabalho, especialmente acerca de sua instrumentalização. A questão central apresentada aos participantes da pesquisa consistia em verificar se continuariam a trabalhar mesmo que herdassem uma quantia que garantisse uma vida com conforto. Os resultados da investigação, que envolveu trabalhadores estadunidenses, mostraram que grande parte permaneceria em atividade mesmo nessas condições, indicando que o trabalho ainda era um elemento central na vida das pessoas, garantindo a integração social, a ocupação do tempo e um propósito de vida. Sua ausência representava sentimentos negativos, como o receio de perder a sanidade, sentir-se inútil ou entediado. Além disso, foram verificadas diferenciações dos significados do trabalho conforme a idade e os grupos ocupacionais. Nesse sentido, a intenção de permanecer trabalhando era maior entre os mais jovens e menor entre os trabalhadores sem qualificação. Ademais, entre os trabalhadores de classe média, trabalhar significava majoritariamente um propósito, um meio para a realização e a autoexpressão. Para os trabalhadores rurais e operacionais, trabalhar significava manterse ativo, ocupado.

Os estudos de Morse e Weiss (1955) foram replicados por Vecchio (1980), que identificou uma queda significativa em relação à centralidade do trabalho, exceto no grupo formado por trabalhadores entre 45 e 54 anos. Os resultados sinalizavam que a "ética de lazer" poderia estar substituindo a tradicional "ética de trabalho" nos Estados Unidos. Embora os resultados verificados nas duas pesquisas tivessem algumas limitações, ambas serviram como fonte de inspiração para diversos estudos sobre o tema, entre os quais se destacam aqueles conduzidos pelo Meaning of Work Research Team (MOW).

A equipe do MOW foi formada por cientistas das áreas de sociologia, psicologia organizacional e do trabalho, psicologia social, economia e gestão, recursos humanos e sociopsicologia do trabalho e das organizações. Os pesquisadores se reuniram em 1978, tendo fundado o The MOW International Research Center em 1980. Considera-se que os resultados obtidos por esse grupo foram os que mais se destacaram no campo dos significados do trabalho e ainda influenciam a maior parte dos estudos sobre o tema (Goulart, 2009). O objetivo dos pesquisadores era identificar a variedade de significados atribuídos ao trabalho por indivíduos e grupos na sociedade industrial, compreender o modo como esses significados se desenvolvem e se distinguem (ou não) diante de diferentes nacionalidades e sistemas culturais, bem como entender as consequências dos 
diferentes significados para os indivíduos, organizações e sociedades (Ruiz-Quintanilla e Claes, 2000).

O MOW adotou a concepção do significado do trabalho como o conjunto de valores, crenças e expectativas que, embora tenham natureza individual, são influenciados pela sociedade por meio de agentes de socialização, como família, instituições de ensino e organizações de trabalho. Os significados do trabalho funcionam como uma estrutura de referência para a ação, por meio da realização de crenças individuais sobre os resultados esperados do trabalho, sobre o que se deve oferecer em dada situação de trabalho no sentido de alcançar esses resultados, bem como acerca da identificação com o trabalho, ou seja, a importância deste para a autoimagem (Ruiz-Quintanilla, 1991). Ademais, é importante esclarecer que o MOW (1987) considerou como trabalho somente as atividades realizadas em troca de salário, excluindo, desse modo, atividades não remuneradas, como o trabalho doméstico e o voluntário.

O modelo proposto pelo MOW é heurístico, ou seja, foi pensado para funcionar como uma diretriz de pesquisa. Pressupõe que os significados do trabalho são determinados por escolhas e experiências vivenciadas pelos indivíduos e pelo contexto social e de trabalho, e considera três níveis em sua operacionalização: variáveis condicionais (antecedentes), em que se relacionam a situação familiar, o contexto profissional atual e passado, além do ambiente micro e macroeconômico; variáveis centrais (dimensões dos significados do trabalho); e consequências dessas significações para o ambiente socioeconômico. As cinco dimensões abarcadas pelo modelo são a centralidade do trabalho, as normas sociais sobre o trabalho, os resultados esperados/valorizados no trabalho, a importância dos objetivos e produtos do trabalho e as definições sobre o ato de trabalhar. Após uma série de estudos de validação, somente as três primeiras dimensões persistiram empiricamente como maiores representações dos significados do trabalho (Ruiz-Quintanilla e Claes, 2000) e, portanto, apenas estas serão descritas aqui.

A centralidade do trabalho é definida como o grau de importância atribuído ao trabalho na vida de um indivíduo em dado momento. Em sua constituição, encontram-se dois componentes teóricos. Um deles, de caráter valorativo, que compreende a avaliação absoluta da importância atribuída ao trabalho. O segundo envolve a análise da importância do trabalho em relação a outras esferas, como a familiar, a religiosa e a do lazer, sendo, portanto, de orientação relativa (Ruiz-Quintanilla e Claes, 2000).

A centralidade absoluta resulta de um procedimento cognitivo que se baseia na comparação entre o trabalho como uma atividade e a percepção do self. Por meio dessa comparação, o trabalho pode emergir como central ou periférico para a autoimagem, sendo parte de um processo de autoidentificação. Contempla, adicionalmente, o envolvimento com o trabalho, partindo de uma resposta afetiva em que este é visto como parte da vida da pessoa (MOW, 1987). A centralidade relativa se orienta na premissa de que os interesses pessoais são segmentados em diferentes subesferas, conforme defendido por Dubin (1956) em seus estudos sobre os "interesses centrais da vida" dos trabalhadores industriais. Nessa 
perspectiva, os indivíduos, embora participem das diversas esferas imprescindíveis à sua socialização, atribuem preferência e maior significado àquelas que oferecem recompensas mais positivas para seus comportamentos.

A centralidade absoluta parte da crença ou orientação valorativa em relação ao self, já a centralidade relativa perpassa um processo decisório de natureza comparativa entre diferentes elementos ou subesferas da vida, em que o trabalho pode emergir, ou não, como aquela de sua preferência. Os investigadores do MOW advertem que essas medidas se correlacionam apenas moderadamente, de modo que a esfera laboral pode, concomitantemente, ocupar uma posição de centralidade e ter seus interesses divididos com outras esferas, ou mesmo ser preterida em relação a elas.

As normas sociais representam os padrões avaliativos sobre o trabalho e se concentram em duas visões normativas: a norma da obrigação e a norma do direito. A primeira parte do ponto de vista individual, centrando-se nos padrões e normas sociais que remetem ao trabalho como uma obrigação para com a sociedade. A normatividade da obrigação como um padrão avaliativo está assente na responsabilidade pessoal ou nas normas internalizadas sobre o dever e o comprometimento social. Essa orientação é marcada pela percepção de que a pessoa deve contribuir, por meio de seu trabalho, para o desenvolvimento da sociedade, tendo a responsabilidade de economizar para sua segurança futura. Ou seja, parte da crença de que a pessoa tem o dever ou a responsabilidade de contribuir para a unidade social por meio do trabalho.

A segunda norma remete aos padrões sociais e normas relacionados ao direito das pessoas e às obrigações da sociedade para com o indivíduo. Relaciona-se à presunção, implícita ou explícita, sobre equidade nas relações de trocas entre as contribuições individuais e o sistema social de recompensa, tendo como um de seus fundamentos o contrato social de Rousseau. A normatividade sobre o trabalho como um direito pode estar relacionada à noção de bem-estar social, assim como à instituição social, e explica, por exemplo, o processo de sindicalização.

A dimensão formada pelos resultados valorizados/esperados no trabalho examina os objetivos individuais na execução dessa atividade, como também a importância relativa destes. Esses objetivos se dividem em expressivos e instrumentais. Os primeiros abarcam o aspecto voltado para a satisfação intrínseca obtida por meio da realização das tarefas, o status ou prestígio social oriundo da atividade realizada, a percepção de que a atividade desempenhada é moralmente valorizada na sociedade, bem como a possibilidade de estabelecer contatos sociais interessantes. Os aspectos instrumentais compreendem o trabalho como uma atividade econômica realizada fundamentalmente para obtenção do sustento e da satisfação de necessidades e como uma atividade capaz de manter um senso de organização e rotina. Nesse sentido, o trabalho funciona como um meio para evitar algumas consequências negativas que são entendidas socialmente como associadas à preguiça e à ociosidade, como o envolvimento com atividades ilegais e criminalidade (Kaplan e Tausky, 1974). 
O modelo enfatiza a reciprocidade como um ponto essencial. Desse modo, os significados do trabalho tanto são afetados quanto alteram a estrutura social, ou seja, as condições culturais e sociais influenciam os significados do trabalho, e estes, por sua vez, afetam a formação de grupos e mudanças sociais (MOW, 1987). A partir do momento em que certos padrões de significados são desenvolvidos por indivíduos e grupos, eles, por sua vez, afetam a sociedade, de modo que o indivíduo define a realidade, mas também é definido por ela. Os autores do MOW evitam entender os significados do trabalho como algo totalmente determinado por forças externas, mas também rejeitam a proposição de que o agente social é o único responsável pela transformação social, reduzindo a interpretação da realidade a critérios meramente subjetivos.

As pesquisas conduzidas pelo MOW (1987) apontaram a centralidade como elemento fundamental para a compreensão do construto. Essa medida deve englobar as justificativas para que uma pessoa avalie o trabalho como algo importante, ou não, em sua vida. A equipe do MOW ressalta, adicionalmente, que as dimensões se relacionam teórica e empiricamente, tendo como um de seus fundamentos a estrutura do mercado de trabalho e das ocupações, o que ajudaria a explicar as diferentes avaliações sobre seus significados e centralidade. Ademais, os resultados obtidos pelo MOW (1987) contribuíram para confirmar a tese de defesa da centralidade do trabalho, ratificando o argumento da manutenção de centralidade mesmo em situações de grande informalidade e precariedade, atestada por diversos autores (Antunes, 2009; Bendassolli, 2007; Castells, 2011; De La Garza e Hernández, 2000). Reforçam, portanto, que o trabalho se mantém como um elemento central na sociedade, mas elucidam que essa valorização pode ter como referência o que se atinge por meio dele, bem como a avaliação daquilo que nele se investe, ou mesmo uma combinação desses fatores.

Além disso, os resultados das pesquisas conduzidas pelo MOW chamaram atenção para as diferenciações entre os componentes dos significados do trabalho conforme o gênero, a idade, a qualidade do trabalho executado, assim como a escolaridade. Essas características influenciaram a percepção da centralidade, das normas relativas aos direitos e obrigações, assim como dos aspectos mais valorizados no trabalho (Ruiz-Quintanilla e Claes, 2000).

Os resultados obtidos tanto nas pesquisas conduzidas pelo MOW quanto em estudos subsequentes indicaram que a importância do trabalho se altera mediante variações sócio-históricas, culturais e individuais. Faz-se mister chamar atenção para a necessidade de voltar o olhar para a influência de fatores como o papel das classes sociais na formação dos significados do trabalho, algo pouco explorado na literatura (Ardichvili e Kuchinke, 2009) e os aspectos socioeconômicos. Desse modo, para favorecer a compreensão do construto é fundamental que se articulem aspectos sociais e econômicos nos processos de significação do trabalho.

Este artigo propõe, portanto, que a influência de alguns elementos socioeconômicos nos significados do trabalho seja analisada, mas também inclui a 
verificação do papel de fatores demográficos, como gênero, idade e religiosidade, nessa relação. É importante ressaltar que há outras abordagens teóricas acerca dos significados do trabalho (Morin, Tonelli e Pliopas, 2007; Rosso, Dekas e Wrzesniewski, 2010; Tolfo e Piccinini, 2007; Tolfo et al., 2011), no entanto, este estudo se ateve essencialmente àquela que orienta os dados fornecidos pela base de dados secundários utilizada.

\section{Metodologia}

Os dados utilizados para as análises foram obtidos através da quinta onda do World Values Survey (WVS) (Inglehart et al., 2018) e referem-se exclusivamente à amostra brasileira. O WVS é constituído por uma rede global de cientistas sociais e teve seu início marcado por uma pesquisa conduzida pelo European Values Survey Group (EVS) em 1981, que contemplou 24 países da Europa (Inglehart et al., 2000). Desde então, as coletas de dados ocorrem de modo sucessivo nas chamadas "ondas", realizadas entre os períodos de 1981 a 1984 (onda 1), de 1990 a 1994 (onda 2), de 1995 a 1998 (onda 3), de 1999 a 2004 (onda 4), de 2005 a 2009 (onda 5), de 2010 a 2014 (onda 6) e de 2017 a 2021 (onda 7). Conforme informado no website $^{3}$ da instituição, atualmente são realizadas pesquisas nacionalmente representativas em quase 100 países, contemplando aproximadamente $90 \%$ da população mundial, tendo como base um questionário comum. As amostras são periodicamente coletadas de modo aleatório em todos os países participantes, abrangendo todas as suas regiões. As entrevistas são conduzidas pessoalmente e no idioma oficial do país participante. Trata-se de um microconjunto de dados, pois contém informações personalizadas para cada indivíduo em diferentes momentos no tempo, ainda que não seja um painel. Os dados da população brasileira constituem uma amostra probabilística formada por 1.500 participantes e foram coletados entre novembro e dezembro de 2006, em parceria com a Universidade de Brasília (UnB).

O projeto WVS aborda atitudes perante diversos fatores, como aspectos religiosos e éticos, relações familiares, avaliação do trabalho, felicidade, saúde e satisfação com a vida, explorando a hipótese de que os sistemas de crenças em massa estão mudando, o que tem importantes consequências econômicas, políticas e sociais. Segundo os organizadores do survey, a análise da transformação no sistema de crenças, bem como seu impacto social, somente seria possível se toda a gama de variações culturais, políticas e econômicas fosse abarcada. A estratégia adotada permitiria fomentar a difusão de técnicas empíricas das ciências sociais nas sociedades em que eram pouco utilizadas anteriormente. Isso se fundamenta na percepção de que a pesquisa ocupa um lugar de relevância na medida em que fornece aos cientistas sociais e tomadores de decisão uma vasta gama de informações valiosas acerca das mudanças sociais, crenças e preferências de massa (Inglehart et al., 2000), que podem, inclusive, embasar o desenvolvimento de políticas públicas. Um de seus destaques é que os dados por ela fornecidos podem ser úteis

\footnotetext{
${ }^{3}$ Disponível em: <http://www.worldvaluessurvey.org>. Acesso em: 16 ago 2019.
} 
para pesquisas que se apoiam em outros referenciais teóricos, até mesmo aqueles não alinhados à vertente teórica em que a pesquisa se embasa (Castro, Ranincheski e Capistrano, 2015).

O projeto WVS foi influenciado por algumas teorias, entre elas a teoria da mudança intergeracional de valores, proposta por Ronald Inglehart, presidente fundador do World Values Survey Association. Essa teoria explora a hipótese de que ocorreram mudanças nos valores entre coortes geracionais em virtude do desenvolvimento do Estado de bem-estar social que emergiu após a Segunda Guerra Mundial. Nessa perspectiva, as mudanças no contexto econômico e social, passando de uma realidade marcada pela fome e privação a um contexto permeado pela segurança econômica em grande parte das sociedades industrializadas, teriam alterado as prioridades individuais daqueles que nasceram na geração pós-guerra. Isso teria levado a uma mudança gradual, por meio da sobreposição de gerações, de valores materialistas (com foco na segurança física e econômica) em direção aos valores pós-materialistas (com ênfase na autoexpressão, liberdade e qualidade de vida). Assim, algumas transformações socioeconômicas, políticas e culturais verificadas na segunda metade do século $X X$, principalmente em sociedades industriais avançadas ou pós-industriais, culminaram na alteração da prioridade de valores básicos, como resultado das alterações nas condições em que ocorre a socialização primária dos indivíduos (Inglehart, 2008).

A mudança da modernização para a pós-modernização se relaciona à percepção de segurança devido à superação da escassez econômica e consequente valorização de outros fatores por parte da sociedade. De certa maneira, podemos relacioná-la à hierarquia de necessidades de Maslow, que atesta que somente com a superação de necessidades fisiológicas básicas, como fome, sono e segurança, o indivíduo busca atingir as necessidades mais elevadas, como as de estima e autorrealização. A teoria que defende a mudança intergeracional de valores está apoiada nas hipóteses de escassez e socialização, que são complementares (Inglehart, 2018). A primeira delas reflete a distinção básica entre as necessidades materiais de sobrevivência e segurança física e as necessidades não materiais, como as de estima, autoexpressão e estética. Como as necessidades materiais são imediatamente cruciais para a sobrevivência, quando elas são escassas, tendem a ter prioridade sobre quaisquer outras necessidades, incluindo as necessidades pósmaterialistas. Porém, estando as condições de segurança garantidas, as pessoas tenderiam a enfatizar os objetivos pós-materialistas, como pertencimento, estima e livre escolha (Inglehart e Welzel, 2005). A hipótese da escassez se assemelha ao princípio da utilidade marginal decrescente proposto na teoria econômica e reflete a distinção entre as necessidades materiais de sobrevivência e segurança física e as necessidades não materiais, como as de autoexpressão e satisfação estética. Isso implica que períodos prolongados de alta prosperidade incentivam a disseminação dos valores pós-materialistas, enquanto o declínio econômico duradouro tem o efeito oposto. 
Já a hipótese da socialização preconiza que os valores individuais estão enraizados na socialização primária, mas se alteram principalmente por meio da substituição intergeracional da população. Cabe ressaltar, contudo, que o impacto das mudanças econômicas na dimensão cultural não é algo simples, já que o processo depende do sentimento de segurança material, que tem cariz subjetivo, parcialmente moldado pelo nível de renda de uma sociedade, mas também por suas instituições de assistência social e sua segurança. Embora a renda per capita seja um indicador das condições que levam a essas transformações, o elemento teoricamente crucial é o senso de segurança existencial. A percepção e a satisfação de cada um variam em decorrência do entorno cultural em que a pessoa foi inserida e daquele em que ela foi socializada. Convém ressaltar que a hipótese da socialização afirma que as prioridades básicas de valor das pessoas não mudam da noite para o dia. Um dos conceitos mais difundidos nas ciências sociais é que a estrutura básica da personalidade se cristaliza quando se chega à idade adulta. Evidências consideráveis indicam que os valores básicos das pessoas são desenvolvidos na primeira socialização e cristalizados quando atingem a idade adulta, mudando relativamente pouco depois disso. A mudança de valor entre gerações ocorre quando as gerações mais jovens crescem sob condições diferentes daquelas que moldaram as gerações anteriores (Inglehart, 2018).

Tomadas em conjunto, as duas hipóteses permitem gerar diversas previsões sobre a alteração nos valores. Enquanto a hipótese da escassez implica que a prosperidade é propícia à disseminação dos valores pós-materialistas, a hipótese da socialização sugere que a mudança de valor social ocorrerá de forma gradual, principalmente através da substituição intergeracional da população. Portanto, os efeitos da mudança econômica nos valores não acontecem de imediato, sendo perceptível a existência de um intervalo de tempo considerável entre as mudanças econômicas e seus efeitos políticos (Inglehart, 2008, 2018).

Nessa perspectiva, os agentes sociais atribuem maior valor subjetivo aos elementos que identificam como carentes, de modo que suas prioridades somente se alteram na medida em que experimentam melhorias socioeconômicas, voltando o interesse para fatores que propiciam sua emancipação. Segundo a teoria do materialismo e pósmaterialismo, os valores passam por dois extremos, que vão da sobrevivência, com ênfase na segurança e estabilidade econômica, à autoexpressão e emancipação, quando se valorizam elementos como a qualidade de vida, democracia, tolerância, igualdade de gêneros e diversidade (Inglehart e Welzel, 2005). A lógica desse argumento, segundo os autores, é que a superação das necessidades de sobrevivência leva ao desenvolvimento da independência não somente no aspecto financeiro, mas também no cognitivo e social. Isso aumenta o senso de autonomia e fomenta a ênfase na liberdade de escolha e, eventualmente, na demanda por participação civil e política. É importante ressaltar, contudo, que o projeto conduzido pelo WVS não prevê nenhum tipo de determinismo da economia ou da cultura. Os resultados verificados até então sugerem que as relações entre 
valores, economia e política são recíprocas, sendo a natureza exata dos vínculos uma questão empírica, e não algo que pode ser determinado a priori (Inglehart et al., 2000).

O esclarecimento acerca dos valores materialistas e pós-materialistas permite, adicionalmente, compreender que a formação de preferências e valores possui uma natureza relacional, sendo influenciada pelo ambiente socioeconômico e cultural (Harpaz e Fu, 2002; Hirvilammi et al., 2019). Há significativas evidências de que esses valores influenciam a percepção dos significados e centralidade do trabalho em uma sociedade (Yeganeh, 2017). Desse modo, salienta-se que a ênfase em aspectos intrínsecos do trabalho marca uma mudança social, ressaltando a preferência por valores pósmaterialistas em detrimento dos materialistas (Cartwright e Holmes, 2006; Hirvilammi et al., 2019; Pyöriä et al., 2017). Assim, sociedades com predominância de valores pósmaterialistas seriam caracterizadas por menor envolvimento com o trabalho e ênfase em lazer e outras atividades (Ruiz-Quintanilla e Wilpert, 1991).

\section{Hipóteses}

Alguns dos primeiros estudos acerca dos significados do trabalho (Morse e Weiss, 1955; Vecchio, 1980) identificaram a idade como um fator de influência no construto, sinalizando que a centralidade do trabalho era maior entre os mais jovens. Em investigações mais recentes, Hajdu e Sik (2018) relataram que a centralidade do trabalho aumentava ao longo do tempo, chegando a um pico por volta dos 45 anos, mas decaía a partir dos 53 anos. Segundo os autores, a explicação para esse declínio se relaciona com o conceito de atividade econômica no decorrer da vida. Ou seja, quando se deixa de ter a atividade laboral como fonte de renda, a importância do trabalho diminui. Além disso, os objetivos relacionados ao trabalho também se alteravam, com uma tendência à valorização de objetivos extrínsecos com o passar da idade. Um padrão similar foi encontrado em contexto sul-americano, que sinalizou aumento da centralidade do trabalho ao longo dos anos, ressaltando o papel da idade em relação às concepções do trabalho (Zubieta et al., 2008). Para os autores, as condições de inserção dos mais jovens no mercado de trabalho são essencialmente precárias, fruto de um cenário de flexibilização nas formas de contratação, o que contribui para a maior valorização de outras esferas, que não a laboral. Desse modo, tem-se como hipótese que a idade exerça influência sobre os significados do trabalho, no sentido de que estes serão mais salientes com o passar do tempo.

Os estudos que envolvem a relação entre gênero e significados do trabalho apresentam resultados divergentes. Alguns sinalizam que os homens estão mais propensos a valorizar objetivos como remuneração e oportunidades de crescimento, reportando maior centralidade em relação ao trabalho (Bastos, Pinho e Costa, 1995). Em direção oposta, outros indicam que a independência, a valorização de metas pessoais e a estimulação intelectual se mostram mais presentes entre mulheres (Oguegbe et al., 2014), que também denotam maior centralidade do trabalho (Kubo, Gouvêa e Mantovani, 2013). 
Entende-se que a avaliação em relação ao trabalho tende a se equalizar nas situações em que as mulheres possuem as mesmas condições de trabalho e acesso a oportunidades de crescimento profissional (Lu, Huang e Bond, 2016), o que não é o caso do cenário brasileiro. Nossa realidade é marcada pela desigualdade entre homens e mulheres no mercado de trabalho. Percebe-se a prevalência da atuação feminina em trabalhos relacionados ao cuidado (Georges, 2011), bem como a diferenciação salarial, na comparação com homens de mesma escolaridade. Além disso, nota-se que as mulheres ainda assumem majoritariamente as atividades domésticas, o que implica a chamada "dupla jornada" e reforça a tendência para alocação em atividades com menor jornada de trabalho remunerado (Queiroz e Aragón, 2015). Tendo-se em conta esse contexto nacional, tem-se como hipótese que os significados do trabalho sejam mais proeminentes entre os homens.

Segundo Harpaz e Meshoulam (2004), o modo como indivíduos lidam com suas expectativas, desejos e expressividade, inclusive na esfera laboral, pode ser orientado pela fé religiosa. A análise de Weber (2004) acerca da doutrina protestante mostrou o modo como os aspectos econômicos e racionais do trabalho foram evidenciados por meio desses princípios religiosos. A pesquisa feita por Arslan (2001) destacou que católicos e protestantes avaliavam o trabalho de modo desigual. A percepção do trabalho como um fim em si mesmo, com ênfase na valorização do dinheiro e da economia, foi mais saliente entre protestantes. A avaliação de que o trabalho duro traz sucesso, sendo visto como condição para uma vida boa, foi maior entre os católicos. Harpaz (1998) sinalizou maior centralidade do trabalho entre trabalhadores de países majoritariamente protestantes, que receberam educação religiosa e que mantinham a prática da religiosidade, o que indicaria a presença de uma ética protestante do trabalho. Similarmente, Cardoso et al. (2009) verificaram, entre brasileiros protestantes, maior motivação para o trabalho em comparação aos membros das demais religiões. Desse modo, espera-se que os protestantes atribuam maior significado ao trabalho, quando comparados com os católicos. Considera-se relevante analisar a influência do elemento religioso entre os significados do trabalho reportado por brasileiros, sobretudo em virtude da expansão do protestantismo no país.

Ardichvili e Kuchinke (2009) ressaltaram a importância da articulação entre aspectos socioeconômicos e os significados do trabalho, especialmente em sociedades estratificadas, como no caso do Brasil. Mejía Reyes (2017) salienta que sociedades desiguais e menos desenvolvidas tendem a apresentar maior centralidade do trabalho, ao passo que em países menos desiguais e mais desenvolvidos economicamente o trabalho tende a ser menos central na vida das pessoas. Segundo o autor, a proposta teórica de valores materialistas e pós-materialistas ajuda a explicar essa relação: em países mais desenvolvidos, nos quais as pessoas possuem maior nível de bem-estar material, elementos não materiais seriam mais valorizados. Já nos países menos desenvolvidos e com maior desigualdade socioeconômica, o trabalho teria maior centralidade exatamente 
por permitir o acesso aos objetivos materiais. Essa diferenciação entre os significados do trabalho conforme aspectos socioeconômicos também se faz presente quando se comparam diferentes classes sociais. As condições materiais e desigualdades sociais podem influenciar a percepção do trabalho, assim como evidenciam diferenças estruturais no acesso a oportunidades.

Considerando a definição de classes sociais por critérios objetivos, como renda e escolaridade, Allan, Autin e Duffy (2014) demonstraram empiricamente que pessoas oriundas de classes sociais mais altas atribuíram maior significado expressivo ao trabalho. Isso ocorre provavelmente devido ao aumento no poder de decisão sobre a carreira e à diminuição de restrições financeiras que eventualmente comprometeriam suas escolhas profissionais. Embora se verifique baixa diferenciação entre as classes no que diz respeito ao desejo de seguir determinada carreira, a possibilidade de contemplar esse anseio deve ser afetada em razão da classe social e da escolaridade do trabalhador (Duffy et al., 2013). Como consequência disso, verificam-se muitos casos em que as classes mais baixas relacionam o trabalho à sobrevivência financeira, ao passo que, entre as classes mais altas, além da valorização financeira, as pessoas buscam atingir necessidades psicológicas mais elevadas, como a satisfação pessoal e a possibilidade de executar algo que viabilize o desenvolvimento de habilidades, bem como a contribuição para a sociedade (Blustein et al., 2002). Em uma investigação que analisou a influência de características pessoais na atribuição de significados do trabalho, Davidson e Caddell (1994) salientaram o efeito da escolaridade e da renda. Os resultados indicaram que as pessoas com maior escolaridade revelaram tendência a avaliar o trabalho como uma carreira ou vocação, de modo que o decréscimo da escolaridade se relacionava à percepção instrumentalizada do trabalho. Portanto, inclui-se nesta investigação a análise da influência desse fator nos significados do trabalho, com a hipótese de que estes são mais proeminentes entre pessoas de menor nível socioeconômico.

Por fim, o modelo de equações estruturais a ser testado leva em consideração a influência da natureza das atividades na atribuição de significados ao trabalho. Steyn e Kotzé (2004) compararam os objetivos e metas relacionados ao trabalho entre trabalhadores que executavam tarefas com diferentes graus de independência e intelectualidade. Os resultados indicaram a valorização do salário e da segurança entre os trabalhadores que atuavam com atividades manuais, que reportaram menor busca por realização. Em contexto sul-americano, Zubieta et al. (2008) identificaram que trabalhadores com maior independência e variedade nas tarefas percebiam o trabalho como uma função expressiva. Tolfo e Piccinini (2007) salientaram que algumas pesquisas realizadas em contexto brasileiro ressaltaram maior percepção de centralidade entre trabalhadores que exerciam atividades mais intelectualizadas. Resultados similares foram reportados por Bendassolli e Borges-Andrade (2011), que destacaram a presença de uma associação positiva e significativa entre a percepção de autonomia e a centralidade do 
trabalho. Desse modo, espera-se que trabalhadores que atuam em tarefas criativas, intelectuais e com independência atribuam maior centralidade ao trabalho.

\section{Análises estatísticas}

Considerando-se os objetivos desta pesquisa ${ }^{4}$, foram realizadas medidas de estatística descritivas, assim como modelagem de equações estruturais (MEE). Todas as análises foram realizadas com apoio do software Stata. A MEE é uma técnica estatística multivariada que combina aspectos da análise fatorial e da regressão linear múltipla, de modo a conjugar modelos determinísticos e modelos de mensuração (Neves, 2018). A modelagem de equações estruturais se baseia em um quadro teórico estabelecido a priori, que será confirmado, ou não, após a coleta e análise dos dados. É importante salientar que a confirmação de um modelo teórico na explicação da estrutura relacional dos dados não exclui a possibilidade de que outros modelos teóricos também sejam adequados (Marôco, 2014). Contudo, é importante que se tenha confiança teórica no modelo que será testado, já que se trata de uma técnica confirmatória, e não exploratória (Neves, 2018). Geralmente, os modelos de equações estruturais são visualizados por meio de diagramas de trajetórias, que contemplam equações de regressão, de modo a estimar efeitos diretos e indiretos das variáveis independentes sobre as dependentes (Neves, 2018) e possuem como elementos básicos as setas e as variáveis. Convencionou-se que as variáveis latentes são representadas dentro de círculos e as manifestas, dentro de retângulos. As relações causais são representadas por setas de sentido único, no sentido da causa para o efeito. As associações são indicadas por setas de duplo sentido, com duas pontas (Marôco, 2014).

A literatura disponibiliza várias medidas de ajuste, geralmente calculadas com o uso de softwares de análises de equações estruturais (Marôco, 2014). Para verificar a qualidade do modelo testado, é importante que se utilizem ao menos um índice incremental, um índice absoluto, assim como o valor da estatística de qui-quadrado dos graus de liberdade associados. Desse modo, considera-se que um modelo que relata os valores de qui-quadrado normatizado, CFI (índice de ajuste comparativo ou comparative fit index) e RMSEA (raiz do resíduo quadrático médio de aproximação ou root mean square error of approximation), geralmente dispõe de informação suficiente para sua avaliação (Hair et al., 2009).

O diagrama de equações estruturais proposto considera a relação empírica entre as dimensões dos significados do trabalho (centralidade absoluta do trabalho, normas sociais relativas a obrigações do trabalho e resultados esperados/valorizados no trabalho)

\footnotetext{
4 Salienta-se que esta investigação não foi submetida ao Comitê de Ética em Pesquisa, pois faz uso de dados secundários agregados e, conforme previsto na resolução 510, de 7 de abril de 2016, do Conselho Nacional de Saúde, artigo 10, parágrafo único: "Não serão registradas nem avaliadas pelo sistema CEP/Conep: V pesquisa com bancos de dados, cujas informações são agregadas, sem possibilidade de identificação individual".
} 
adotadas pelo MOW (1987), assim como algumas características demográficas e estruturais indicadas previamente na seção em que se elencaram as hipóteses da investigação, conforme se visualiza na Figura 1. Em consonância com o referencial teórico, entende-se como trabalho somente as atividades realizadas em troca de remuneração.

A centralidade absoluta (CTR) é acessada por meio do item: Indique em que medida o trabalho é importante para sua vida. A escala de respostas varia entre 1 (muito importante) e 4 (não é importante). Contudo, para facilitar a análise dos resultados, a escala foi invertida, de modo a variar entre 1 (não é importante) e 4 (muito importante). Em estudos anteriores, Hajdu e Sik (2018), Parboteeah e Cullen (2003) e Mejía Reyes (2017) investigaram a centralidade do trabalho por meio dessa mesma variável, fornecida no questionário do WVS.

A medida referente às normas relativas a obrigações do trabalho (N1 a N5) é acessada através de cinco itens: Para desenvolver inteiramente suas habilidades, o(a) $\mathrm{Sr}(\mathrm{a})$. precisa de um emprego; É humilhante receber dinheiro sem ter trabalhado para isso; As pessoas que não trabalham ficam preguiçosas; Trabalhar é uma obrigação para com a sociedade; O trabalho deve vir sempre em primeiro lugar, mesmo que isso signifique menos tempo livre. Para esses itens, a categoria de respostas variou de concordo totalmente (1) a discordo totalmente (5). Para facilitar a análise dos resultados a escala de respostas também foi recodificada, passando a variar entre discordo totalmente (1) a concordo totalmente (5). Essa medida foi validada em estudos conduzidos pelo MOW (1987), por Parboteeah, Hoegl e Cullen (2009) e por Den Dulk et al. (2013).

Em consonância com investigações prévias (Klonoski, 2014; Salinas-Jiménez et al. 2010; Steyn e Kotzé, 2004), os resultados e objetivos valorizados no trabalho (OBJ) foram acessados por meio da seguinte indagação: Gostaria de perguntar sobre as coisas que seriam mais importantes para o(a) $\mathrm{Sr}(a)$., se estivesse procurando emprego. Vou ler algumas coisas que muitas pessoas levam em conta em relação a seu trabalho. Se o(a) $\mathrm{Sr}(a)$. estivesse procurando emprego, o que o(a) $\mathrm{Sr}(\mathrm{a})$. colocaria em primeiro lugar? As opções de resposta para esse item são: 1- Um bom salário, para não se preocupar com dinheiro; 2- Um emprego seguro, sem risco de fechar, ou de desemprego; 3- Trabalhar com pessoas que o(a) $\mathrm{Sr}(\mathrm{a})$. gosta; 4- Fazer um trabalho importante para se sentir realizado. Foi levada em consideração a organização ordinal da escala de respostas, que parte de uma perspectiva de valorização de objetivos extrínsecos a intrínsecos.

As características demográficas abarcadas no modelo são idade, sexo e religião. As características estruturais incluem o nível socioeconômico e a natureza das atividades desempenhadas. Desse modo, o MEE contempla, adicionalmente, as seguintes variáveis:

ID: idade medida por meio de variável contínua e se refere à idade do entrevistado no momento de aplicação do questionário. 
SX: sexo, variável binária ${ }^{5}$ (dummy), sendo o sexo feminino codificado como 0 e o masculino como 1.

CA: católico, variável binária, sendo $1=$ católico e 0 = não católico.

PR: protestante, variável binária, sendo $1=$ protestante e $0=$ não protestante.

NSE: construto latente referente ao nível socioeconômico, estimado por meio das variáveis relativas a nível educacional (EDU), classe (CLA) e rendimentos (RE) informados pelos respondentes. No questionário do WVS, os níveis de escolaridade variam de 1 (não frequentou a escola) a 9 (ensino superior completo). A classe social varia entre cinco níveis, de 1 (classe alta) a 5 (classe baixa). Essa escala foi recodificada, de modo a apresentar orientação crescente, conforme os demais elementos que compõem o NSE. Desse modo, passou a variar entre 1 (classe baixa) e 5 (classe alta). O rendimento varia do nível mais baixo de salários ao nível mais alto de salários, em uma escala que vai de 1 a 10 . A quinta onda do WVS não forneceu dados sobre a escolaridade dos pais ou sobre o status socioeconômico da ocupação do pai, impossibilitando a estimação do status socioeconômico (SSO), conforme utilizado por Blau e Duncan (1967). Desse modo, esperase obter uma aproximação.

NATIV: construto latente que se refere à natureza da atividade laboral, formado pelas variáveis: $\mathrm{NI}=$ Natureza intelectual da tarefa executada, com uma escala de respostas que varia entre mais tarefas manuais (1) e mais tarefas intelectuais (10); NC = Natureza criativa das tarefas desempenhadas, em uma escala que varia entre 1 (mais tarefas repetidas) e 10 (mais tarefas criativas); e NIND: Independência na execução das tarefas. A escala de respostas varia entre nenhuma independência (1) e total independência (10).

ST: construto latente referente aos significados do trabalho. Essa estrutura se baseia na mensuração teórica proposta pelo MOW, na qual as dimensões mais representativas dos significados do trabalho são a centralidade absoluta (CTR), as normas relativas ao trabalho (de $\mathrm{N} 1$ a $\mathrm{N} 5$ ) e os objetivos e metas relacionados ao trabalho (OBJ).

\footnotetext{
5 O World Values Survey fornece a identificação binária, utilizando a nomenclatura sexo (e não gênero). Segundo a metodologia de aplicação do questionário, o entrevistador deve anotar se o respondente é do sexo masculino ou feminino, sem perguntar sua identificação. As análises quantitativas realizadas neste artigo tendem a utilizar a nomenclatura adotada no survey.
} 
Figura 1

Diagrama teórico proposto do modelo de equações estruturais completo para explicação dos significados do trabalho

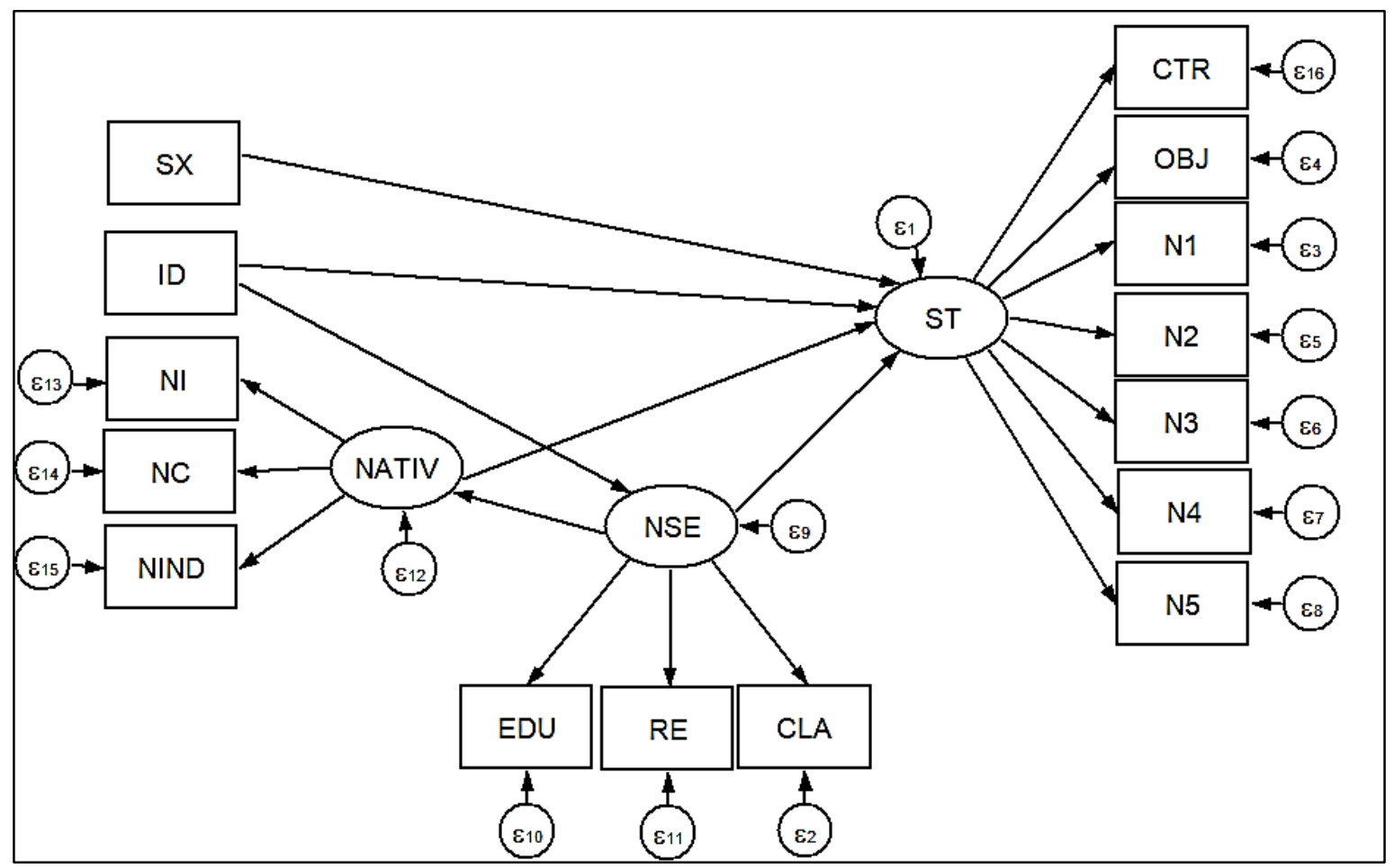

Fonte: Elaborado pelos autores.

\section{Resultados}

Em relação ao perfil dos respondentes, 58,4\% eram do sexo feminino e $41,6 \%$ eram do sexo masculino. A maior parte era casada $(41,27 \%), 26,40 \%$ eram solteiros e $16,67 \%$ viviam com alguém, embora não fossem casados. A média de idade foi de 39,93 anos $(D P=15,71)$. Acerca da escolaridade, um terço dos entrevistados afirmou possuir o ensino fundamental incompleto $(33,3 \%)$, aproximadamente um quarto deles possuía o ensino médio completo $(25,47 \%)$ e $15,6 \%$ possuíam ensino superior completo ou incompleto. A maioria $(51,87 \%)$ trabalhava no momento da pesquisa, seja como autônomo, trabalhador integral (mais de 30 horas/semana) ou em meio período (até 30 horas/semana). Entre os que não trabalhavam, 16,07\% estavam desempregados, 13,2\% eram aposentados, $11,53 \%$ eram donas de casa e $4,93 \%$ eram estudantes.

Os resultados indicaram que os brasileiros atribuíram forte centralidade absoluta ao trabalho. A maioria $(65,4 \%)$ indicou atribuir forte importância a essa categoria, avaliando-a com o grau máximo de importância. Adicionalmente, 33,4\% disseram que o trabalho era importante. Nota-se que apenas $1,2 \%$ dos participantes não atribuiu importância ao trabalho em suas vidas. É interessante ressaltar que, na comparação com 
outras esferas, somente a familiar ocupa posição de maior destaque. Entre os participantes, $99,5 \%$ classificaram a família como importante ou muito importante $(M=$ $3,85, D P=0,38)$, e $98,8 \%$ atribuíram essa avaliação ao trabalho $(M=3,64, D P=0,51)$. No que concerne à religião, essa classificação foi demonstrada por $91 \%$, fazendo desta a terceira esfera mais valorada $(M=3,38, D P=0,72)$, e, por fim, o lazer, que foi valorizado por $84,7 \%$ da amostra $(M=3,09, D P=0,70)$. Esses dados indicam que, ao se aferir a centralidade relativa do trabalho, essa esfera foi a segunda colocada, sendo que, proporcionalmente, apenas a família foi mais valorizada.

A análise dos resultados enalteceu a forte orientação para a normatividade do trabalho como uma obrigação social. O exame pormenorizado desse indicador mostra que $71 \%$ dos respondentes acreditavam que, para que pudessem desenvolver seus talentos, precisavam de um emprego $(M=3,77, D P=1,07)$, reforçando que o trabalho é o meio primordial para o desenvolvimento de suas habilidades. Mais da metade $(56,7 \%)$ afirmou achar humilhante receber algum dinheiro sem trabalhar, o que reforça a percepção de que o trabalho é visto como um meio moralmente aceito para obtenção de dinheiro $(M=3,49$, $D P=1,16)$. Novamente a moralidade do trabalho foi reforçada com a avaliação de que as pessoas que não trabalham se tornam preguiçosas, compartilhada por $74,2 \%$ dos brasileiros participantes do estudo $(M=3,83, D P=1,04)$. A grande maioria (76\%) afirmou entender que o trabalho era um dever para com a sociedade $(M=3,86, D P=0,96)$ e $65,9 \%$ julgaram que o trabalho deveria vir em primeiro lugar, mesmo que isso significasse ter menos tempo livre $(M=3,60, D P=1,1)$. A presença dessas normas indicia que 0 indivíduo percebe o dever de cumprir uma obrigação para com a sociedade, devendo contribuir para o desenvolvimento desta por meio de seu trabalho. Essa normatividade preconiza, adicionalmente, que todos possuem o dever de valorizar o trabalho, independentemente de sua natureza. Assim como postulado na ética protestante salientada por Weber (2004), essa categoria é geralmente vista como o principal meio para a garantia de dignidade.

Em relação aos resultados e objetivos valorizados no trabalho, a maior parte valorizou a segurança $(46,67 \%) ; 28,27 \%$ priorizaram a realização de um trabalho importante, em que possam se sentir realizados; $16,27 \%$ priorizaram um bom salário; e $8,40 \%$ priorizaram o relacionamento com os colegas. Evidenciou-se, portanto, a valorização de um objetivo extrínseco por meio do trabalho, já que os participantes salientaram a importância da segurança na esfera laboral. Essa necessidade pode estar relacionada ao índice de desemprego no país, que reflete um cenário socioeconômico marcado por incertezas. Salienta-se, contudo, que o segundo objetivo mais valorizado pelos participantes remete a um fator intrínseco. A identificação da necessidade de fazer algum trabalho importante, em que se sinta realizado, pode ser um indicativo da importância da vinculação social por meio do trabalho, tido como uma esfera que confere realização e dignidade às pessoas. 
Em relação à modelagem de equações estruturais, a qualidade de ajustamento do modelo teórico proposto foi aferida de acordo com os índices de qualidade propostos por Hair et al. (2009). Embora o modelo inicial tenha apresentado índices de qualidade de ajuste favoráveis, os resultados indicaram que havia trajetórias não significativas. Desse modo, foram feitas modificações que deram origem a um modelo mais parcimonioso, conforme reportado na Figura 2, em que se visualizam os pesos fatoriais padronizados. $O$ modelo final revelou uma qualidade de ajuste satisfatória $\left(x^{2} / \mathrm{df}=4,60, p<0,001\right.$; CFI $=$ 0,969; TLI $=0,960 ;$ SRMR $=0,045 ;$ RMSEA $=0,05, p=0,50)$. Esses valores estão de acordo com o referencial proposto (Hair et al., 2009; Marôco, 2014). O coeficiente de determinação (CD), que indica a proporção da variância total explicada pelo modelo, considerando todas as variáveis incluídas (Neves, 2018), foi de 0,951. O teste de significância da estatística de qui-quadrado pode ter tido um valor significativo devido ao tamanho amostral (Marôco, 2014) e não deve ser avaliado sozinho (Hair et al., 2009). Os valores de CFI, RMSEA e SRMR (raiz padronizada do resíduo médio ou standardized root mean residual) sustentam a qualidade do modelo (Hair et al., 2009).

Figura 2

Modelo final de equações estruturais para explicação dos significados do trabalho (coeficientes padronizados)

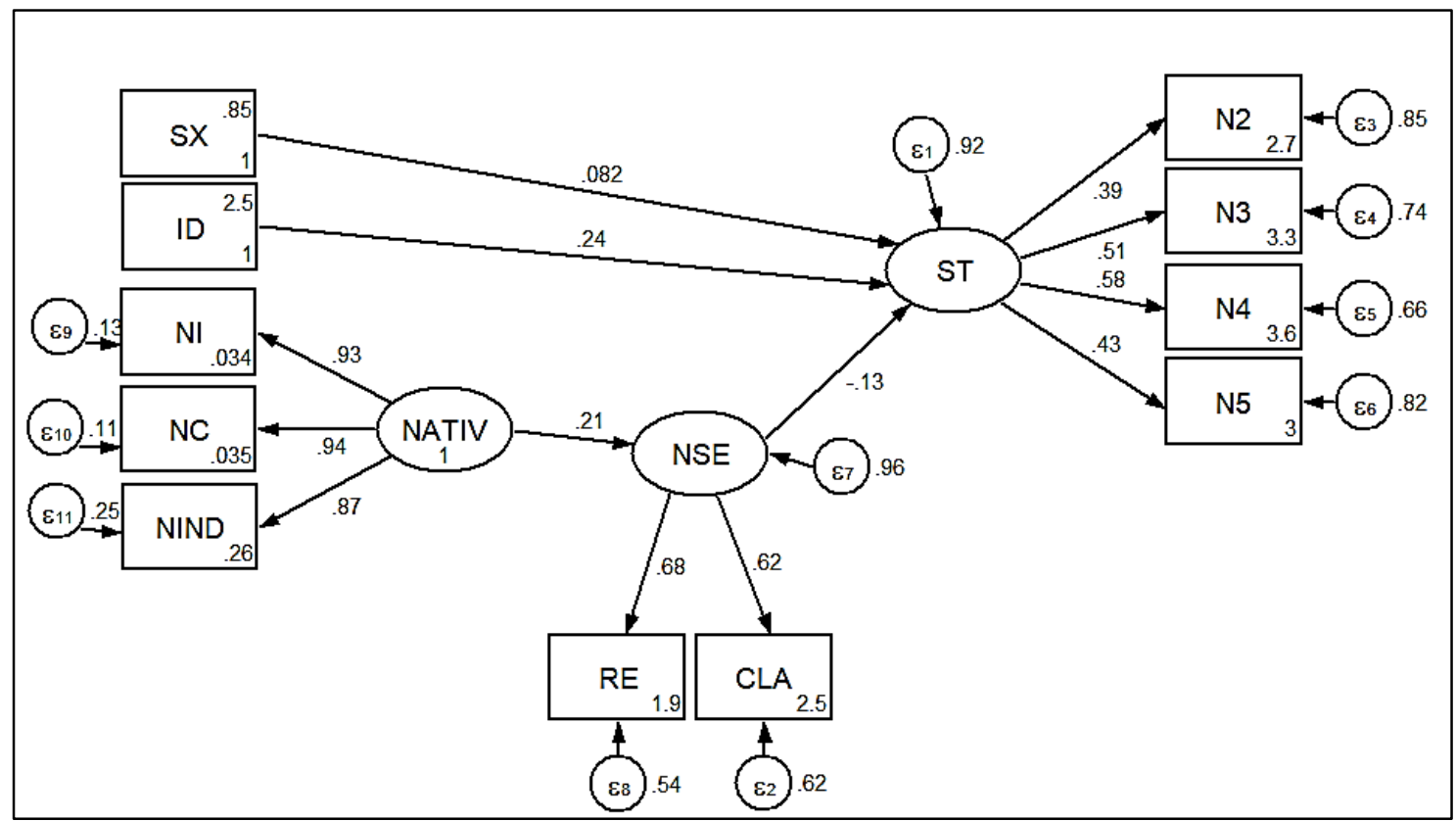

Fonte: Elaborado pelos autores.

A modelagem de equações estruturais sinalizou que apenas as normas sociais convergiram para o construto dos significados do trabalho, o que pode ser interpretado como um forte indicativo da centralidade cultural dessa esfera em nossa sociedade. Esses resultados sinalizam uma intensa normatização dessa categoria como uma obrigação 
social, o que novamente contribui para ressaltar a disseminação da ética do trabalho (Weber, 2004). Dessa forma, faz-se patente a forte presença da normatização do trabalho como uma obrigação social, reforçando a centralidade dessa categoria em nossa sociedade.

Os resultados da modelagem de equações estruturais evidenciaram um efeito positivo e direto da idade em relação aos significados do trabalho $(\beta=0,24, p<0,001)$, indicando que o aumento da idade se relaciona com a maior percepção de sua centralidade e normatividade, o que sugere a confirmação da hipótese colocada. Desse modo, a atribuição de relevância ao trabalho, assim como da importância de contribuir para o desenvolvimento social por meio dessa atividade, tende a se consolidar no decorrer dos anos.

Um padrão semelhante foi encontrado em contexto sul-americano por Zubieta et al. (2008), que identificaram o aumento da centralidade do trabalho com o acréscimo da idade. Os resultados verificados pelos autores demonstraram que, em comparação com trabalhadores mais jovens (entre 18 e 25 anos), os participantes com mais de 26 anos indicaram maior centralidade laboral. Uma das explicações para esse aumento da centralidade estaria relacionada com as condições de inserção dos mais jovens no mercado de trabalho, que seriam marcadas por um contexto de forte precariedade. Ao vislumbrarem um cenário laboral permeado pela flexibilização nas formas de contratação, os trabalhadores mais jovens teriam uma tendência a valorizar outras esferas, que não a laboral. Entende-se, contudo, que no decorrer do amadurecimento tem-se a consolidação de uma valoração moral daquilo que representa a condição de ser trabalhador, conforme destacado em resultados observados na literatura (Alonso et al., 2016; Mattos e Chaves, 2006).

Os dados trazem indícios de confirmação da hipótese de que o gênero exerce influência nos significados do trabalho, de modo que o modelo final indicou um efeito direto do sexo nos significados do trabalho $(\beta=0,082, p=0,017)$. Dessa maneira, pode-se afirmar a tendência de os homens atribuírem maior centralidade ao trabalho em comparação com as mulheres. Esses resultados se assemelham aos verificados por Mejía Reyes e Martín Artiles (2018), que identificaram a presença de maior centralidade do trabalho entre os homens estadunidenses. Tais resultados foram explicados pelo fato de as mulheres ainda ocuparem de maneira significativa a esfera doméstica, voltada para o cuidado familiar, o que dificulta sua inserção no mercado de trabalho remunerado. Nos casos em que conseguem entrar no mercado laboral, as mulheres ainda ocupam espaços marcados pela informalidade e por desigualdades salariais.

Em sequência, foi analisada a hipótese de que a religião exerceria efeito nos significados do trabalho, de modo que os protestantes atribuiriam maior centralidade quando comparados aos católicos. Os resultados da modelagem de equações estruturais não indicaram efeitos estatisticamente significativos da religião em relação aos significados do trabalho e não permitiram, portanto, sustentar tal afirmação. Assim, não foram encontrados elementos que permitissem a confirmação dessa hipótese. Ali, Falcone e Azim 
(1995) afirmaram que a amplitude do fluxo de informações, a extensa mobilidade, bem como a forte interação social na sociedade contemporânea, podem diminuir as diferenças em atitudes referentes ao trabalho que seriam atribuídas a um determinado grupo religioso. Os autores também não encontraram diferenças em relação à ética do trabalho ao comparar católicos e protestantes. Geser (2009) identificou que a atitude positiva em relação ao trabalho estava relacionada à fé cristã em geral, não havendo distinção entre essas afiliações.

A natureza das atividades indicou possuir um efeito indireto de -,0273 nos significados do trabalho, o que se efetiva por meio do nível socioeconômico, este com um efeito direto negativo $(\beta=-0,13, p=0,005)$. Ou seja, quanto maior o nível de intelectualidade, criatividade e independência nas atividades executadas, mais elevado tenderia a ser o nível socioeconômico ocupado e mais baixa tenderia a ser a percepção de significados do trabalho. O trabalho tenderia a ser, portanto, mais central entre aqueles com estatuto socioeconômico mais baixo e que atuam com atividades de natureza repetitiva e manual, e realizadas com menor independência. Salienta-se que a variável latente NSE se mostrou mais bem ajustada quando mensurada por meio da classe social e da escala de rendimentos, de modo que a escolaridade foi excluída do construto.

\section{Conclusões}

Este artigo buscou investigar os significados do trabalho entre os brasileiros, bem como a influência de elementos demográficos e estruturais nessa atribuição. Os resultados descritivos permitiram identificar uma alta valorização do trabalho por parte dos brasileiros, sinalizando a presença de forte centralidade da esfera laboral e também a intensa inclinação para a percepção do trabalho como uma obrigação social. Por meio da modelagem de equações estruturais, não foi possível confirmar a estrutura dos significados do trabalho formada pelas três dimensões sinalizadas pelos estudos do MOW. No entanto, verificou-se que características demográficas, como sexo e idade, assim como fatores estruturais, especificamente a natureza das atividades e o nível socioeconômico, influenciaram os significados atribuídos ao trabalho.

Ressalta-se que somente as normas sociais relativas a obrigações convergiram para o construto, diferenciando-se da estrutura de dimensões indicada no modelo heurístico do MOW (1987). Kubo, Gouvêa e Mantovani (2013) sistematizaram resultados de estudos que replicaram o modelo do MOW e sinalizaram diferenças em relação à organização de suas dimensões, embora tenham usado como ponto de partida o modelo composto pelas três dimensões (centralidade, normas sociais e objetivos). Pérezgonzález e Vilela (2005), por exemplo, verificaram uma estrutura bidimensional, em que se salientam os motivos e valores, como papéis do trabalho e conforto, e as crenças normativas, que resumem a centralidade, deveres, direitos e contribuição social. Os estudos de Soares (1992, apud Kubo, Gouvêa e Mantovani, 2013) verificaram um modelo 
composto pelas dimensões centralidade do trabalho, centralidade da família, centralidade da religião, resultados sociais, resultados econômicos, objetivos intrínsecos e objetivos extrínsecos.

Como salientaram Ruiz-Quintanilla e Claes (2000), o entendimento do trabalho como uma obrigação parte da percepção partilhada de que todos devem trabalhar para garantir o desenvolvimento da sociedade. A noção de obrigação para com o trabalho no nível de um país é tida como um valor cultural profundo, sinalizando um conjunto de crenças amplamente partilhado por seus membros, e reflete a presença da centralidade cultural do trabalho, na qual se entende que essa categoria é valorizada e vista como um dever e uma obrigação para com a sociedade (Den Dulk et al., 2013).

Salienta-se, dessa maneira, a percepção de que o trabalho ocupa uma posição de relevância social e centralidade entre os brasileiros, em consonância com outras pesquisas realizadas no país (Bastos, Pinho e Costa, 1995; Kubo e Gouvêa, 2012; Kubo, Gouvêa e Mantovani, 2013). Conforme destacou Mejía Reyes (2017), sociedades que apresentam maior desigualdade social e menor distribuição de riquezas, como é o caso do Brasil, tendem a apresentar maior centralidade do trabalho quando comparadas a nações mais desenvolvidas e menos desiguais. Segundo o autor, isso é explicado pela proposta teórica do pós-materialismo, pois, uma vez que os agentes sociais determinam maior valor subjetivo aos elementos da vida que são mais carentes, à medida as suas condições econômicas e sociais melhoram, eles passam a ter outras prioridades. Em consonância com os resultados identificados por Yeganeh (2017), que verificou empiricamente a associação entre os valores pós-materialistas e a centralidade do trabalho, pode-se sugerir que a alta valorização conferida a essa esfera pelos brasileiros estaria relacionada ao desenvolvimento socioeconômico do país. Portanto, ainda que muitos se deparem com uma realidade de trabalho precarizado e até mesmo degradado, o cenário nacional não possibilita que a superação das necessidades de sobrevivência e segurança seja vivenciada pela maioria.

Como ressaltado anteriormente, essa proposta teórica advoga que os valores se orientam por dois extremos: um marcado pela sobrevivência, em que se exprime ênfase na importância da estabilidade econômica e da segurança, e outro, em que os valores de autoexpressão atribuem prioridade a valores de emancipação, como igualdade entre gêneros, tolerância com a diversidade e a diferença, entre outros. Em 2006, no eixo sobrevivência/autoexpressão, o Brasil pontuava aproximadamente 0,5 (em uma escala que varia entre -2 e +2 ), próximo a países como Venezuela e Peru.

A relação entre centralidade do trabalho e necessidade de sobrevivência também pode ser identificada por meio da análise da centralidade relativa dessa esfera. Os resultados sinalizaram que, entre os brasileiros, o trabalho foi, majoritariamente, preferido em relação ao lazer. O estudo de Yeganeh (2017) sinalizou que a opção por preterir o lazer, favorecendo a escolha do trabalho, é uma característica típica das sociedades menos desenvolvidas, em que a sobrevivência ainda é tida como um elemento a ser superado. 
Desse modo, chama-se atenção para a atribuição do significado voltado para a garantia da sobrevivência, que se revela distinta do significado econômico conferido por pessoas em países desenvolvidos (Borges, 1999), envolvidos na maioria dos estudos conduzidos pelo MOW.

A presença da forte normatividade do trabalho como uma obrigação social se relaciona com a centralidade cultural dessa categoria na sociedade. Essa centralidade estaria associada à importância do trabalho na vida dos indivíduos e da comunidade, incluindo a crença de que o trabalho é um dever para com a sociedade. Segundo Hirschfeld e Feild (2000), a atribuição de importância ao trabalho se baseia em uma noção normativa, estando fortemente associada à ética protestante do trabalho. Verifica-se, portanto, indícios da presença de uma ética do trabalho profissional racional em que a atividade é ressaltada como o principal meio para garantia da dignidade às pessoas. Aqueles que não a executam tendem a não ser vistos como indivíduos moralmente relevantes para a sociedade, de modo que se incentiva que o trabalho seja objetivo de todos, o que se aproxima da ética do trabalho weberiana. Como ressalta Zubieta (2012), a saliência dessa normatividade é verificada em países mais conservadores, menos desenvolvidos e mais desiguais. Para a autora, uma vez que os países atingem um certo nível de desenvolvimento econômico, essa normatividade pautada na ética do trabalho tende a decair, permitindo a emergência de outros interesses. Portanto, é esperado haver uma forte correlação entre a centralidade e tal normatividade, já que ela capta, justamente, as atitudes relacionadas à centralidade do trabalho (Yeganeh, 2017). Assim, a forte centralidade reportada na amostra brasileira e a convergência das normas sociais para o significado do trabalho, algo visualizado na modelagem de equações estruturais, podem ser indicativos dessa centralidade cultural.

A maior atribuição de significados e o aumento na percepção de centralidade do trabalho com o passar da idade, algo verificado neste estudo, também foram sinalizados nas pesquisas de Mejía Reyes e Martín Artiles (2018) e Warr (2008). No contexto brasileiro, Bastos, Pinho e Costa (1995) verificaram menor centralidade do trabalho, assim como maior discordância em relação às normas do trabalho entre trabalhadores em fase inicial na carreira, portanto mais jovens, em comparação com aqueles que estavam em uma etapa mais avançada da vida laboral. Esses resultados indicam que a percepção do trabalho como um elemento central, como um dever pessoal e coletivo se consolida com o decorrer da idade. Enquanto os mais jovens priorizam outras esferas, como a social, os mais velhos percebem o trabalho como um dever, como um meio para obtenção de recursos econômicos e sustento (Zubieta, 2012).

Entende-se, dessa maneira, que a noção de que o trabalho atua como um dos principais meios para inserção do indivíduo na sociedade, assim como a ênfase na importância de contribuir socialmente, tende a se solidificar com o passar dos anos, o que se reflete na valorização da manutenção desse vínculo, e, consequentemente, na sustentação da centralidade do trabalho. Nessa direção, os achados sinalizaram que a 
consolidação do trabalho como uma obrigação social se evidenciava com o aumento da idade, indiciando efeitos de uma socialização que prepara os indivíduos para o trabalho, favorecendo a sua valorização ao fomentar a ideia de que essa categoria funciona como uma fonte digna e moralmente aceita para a vinculação do indivíduo ao tecido social.

Os resultados sinalizaram a diferenciação entre os significados do trabalho conforme o gênero dos participantes, indicando que, entre os homens, há maior entendimento de que o trabalho constitui uma obrigação para com a sociedade, o que estaria relacionado a uma maior centralidade do trabalho, situação semelhante à reportada por Mejía Reyes e Martín Artiles (2018) e por Bastos, Pinho e Costa (1995). Essa diferença seria reflexo da desigualdade no acesso ao trabalho, assim como da percepção de que os homens ainda ocupam majoritariamente o espaço público relacionado ao labor e ao prover, ao passo que as mulheres estariam mais voltadas para as esferas domésticas e do cuidado, com sérias limitações para o acesso a espaços e posições mais privilegiados. Isso porque as condições de trabalho das mulheres, apesar de sua incorporação crescente no mercado de trabalho, são geralmente mais precárias e desiguais em relação aos benefícios salariais e sociais (Hirata, 2018; Mejía Reyes e Martín Artiles, 2018). É importante ressaltar que a inserção das mulheres no mercado de trabalho tem crescido no país, e muitas delas são, inclusive, responsáveis pelo sustento e manutenção de suas famílias. Ainda assim, a desigualdade se faz presente, sendo que as mulheres possuem menor jornada semanal, bem como menor acesso a posições mais elevadas e com maior remuneração (Madalozzo, Martins e Shiratori, 2010). Portanto, esse histórico de desigualdades e a responsabilização concomitante pelas esferas da família e do cuidado podem contribuir para que o trabalho remunerado não seja um elemento tão central na vida das mulheres (Torgler, 2012). As práticas de socialização primária muitas vezes reverberam que as mulheres devem assumir funções pensadas para absorver características definidas socialmente como femininas, como atividades voltadas para o cuidado e o afeto, por vezes classificadas como menos complexas (Saboya, 2015). Identificam-se, dessa maneira, indícios da socialização de alguns estereótipos de gênero, disseminados por meio de figurações (Elias, 1994) que visam à manutenção de certos tipos de privilégio e poder, influenciam as posições ocupadas pelas mulheres e acabam por induzir o modo como elas atribuem significados ao trabalho.

Neste artigo, não foram verificadas diferenças nos significados do trabalho entre católicos e protestantes. Segundo Ali, Falcone e Azim (1995), isso pode indicar que a amplitude do fluxo de informações e também as extensas interações sociais na sociedade atual e a mobilidade podem ajudar a reduzir as diferenças nas atitudes relacionadas ao trabalho que são atribuídas a um determinado grupo religioso. Desse modo, entende-se que a atitude positiva em relação ao trabalho pode estar relacionada à fé cristã em geral, não havendo distinção entre as respectivas afiliações (Geser, 2009). Além disso, como a igreja está imersa em um contexto impulsionado por marcadores econômicos, essa instituição se vê obrigada a desempenhar um papel de promoção da ética do trabalho, de modo a contribuir para o crescimento da economia e a sua estabilidade. Assim, cada 
proclamação da igreja deve ser entendida como um ato econômico, já que até mesmo os resultados do sistema capitalista se inserem como uma oferta para a religião. Reforça-se, portanto, o papel notável que a igreja desempenha ao inculcar uma ética do trabalho que atua como força motriz da atividade econômica (Steenkamp, 2013).

A atribuição de maior significado ao trabalho por parte das pessoas que atuam em tarefas manuais, repetitivas e marcadas por menor grau de independência, e ocupam posições socioeconômicas mais baixas, pode ter sua explicação ancorada na perspectiva do pós-materialismo apresentada por Inglehart (2008, 2018). Como explanado anteriormente, os agentes sociais atribuem maior valor subjetivo aos elementos que garantem sua subsistência e segurança, e, somente quando estes são atingidos, os valores relacionados à expressão e à emancipação podem ser vislumbrados. Assim, os aspectos socioeconômicos conformam os valores associados ao trabalho, sendo esperado haver maior centralidade do trabalho em situações marcadas por condições socioeconômicas mais desfavoráveis (Yeganeh, 2017). Nessa direção, entende-se que o trabalho seria mais central para aqueles com menor nível socioeconômico porque o não trabalho estaria associado à não garantia de sua sobrevivência, à não existência. Dessa maneira, essa categoria seria fundamental para a emergência do senso de segurança existencial.

É importante salientar que o trabalho é um meio para que se possam suprir necessidades básicas, como as de segurança, alimento e abrigo, mas também pode prover recursos sociais, como status e prestígio. Contudo, para que o indivíduo possa voltar sua atenção e interesse para objetivos mais elevados, ele precisa que esses elementos básicos sejam minimamente supridos. Isso pode sinalizar que os caminhos para a dotação de significado ao trabalho tendem a passar pelo acesso a oportunidades, de modo que, embora também sejam marcados por aspectos e escolhas individuais, estejam fortemente relacionados ao contexto social e econômico vivenciado (Blustein et al., 2002).

Pode-se entender que o desequilíbrio socioeconômico, ao influenciar tanto o habitus como as disposições, figurações e relações de poder, contribui para a diferenciação das ocupações/profissões e posições que cada um tende a acessar no campo laboral. Os agentes sociais ocupam posições distintas no campo social, de modo que percebem a realidade de modo desigual, construindo diferentes significados sobre o trabalho. Essas posições são influenciadas pelo volume de capital desses agentes, contudo as lutas que estabelecem nesses campos também alteram a distribuição desse capital, modificando sua estrutura.

Por fim, os resultados aqui obtidos sinalizam que os fatores sociodemográficos e estruturais elencados contribuem para influenciar os trajetos que levam à formação dos diferentes significados compartilhados sobre o trabalho, sinalizando caminhos distintos na socialização dos indivíduos, caminhos estes que ajudam a conformar, de alguma maneira, as posições que esses sujeitos ocupam nos espaços sociais. Essas posições influenciam a percepção social do trabalho e dos seus significados. Mas, ao mesmo tempo em que as representações compartilhadas sobre o trabalho se constroem a partir dessas posições, 
elas alteram tais posições e a dinâmica do campo social, modificando a realidade, bem como as ações e percepções desses agentes sociais. Os resultados aqui verificados permitiram, portanto, elucidar que a conformação dos significados do trabalho passa por caminhos muito mais complexos do que aqueles pautados em aspectos singulares, como a mera aproximação entre ocupações e áreas de atuação profissional.

Embora este artigo tenha atingido seus objetivos, tendo contribuído para a compreensão dos significados do trabalho entre brasileiros, assim como de elementos que influenciam em sua diferenciação, é importante ressaltar suas limitações. Ainda que a amostra utilizada seja probabilística e, portanto, representativa da população brasileira, os dados retratam a situação no país em 2006, algo que difere dos dias atuais em alguns aspectos. A título de exemplo, segundo dados do IBGE, em 2006 o país tinha uma taxa de desemprego de $8,41 \%$, e, no primeiro trimestre de 2019 , essa taxa saltou para $12,4 \%$. Em 2006, 19,31\% dos brasileiros viviam abaixo da linha de pobreza e, em 2019, 25\% estavam nessas condições. Portanto, faz-se necessário o desenvolvimento de pesquisas em contexto atual, de modo que se possa aprofundar a análise dos significados do trabalho.

Uma melhor compreensão da influência dos fatores demográficos e estruturais aqui ressaltados pode ser atingida, complementarmente, por meio de abordagens qualitativas. A comparação dos significados do trabalho entre grupos formados por pessoas de diferentes gêneros, idades e posições socioeconômicas, assim como entre pessoas que atuam em atividades de natureza distintas, pode favorecer o entendimento do modo como esses fatores conduzem a diferentes trajetórias e, por conseguinte, contribuem para diferenciar as atribuições de significados do trabalho. Ademais, o trabalho foi abordado somente em seu aspecto remunerado, sendo importante acessar as percepções sobre os significados referentes a outras modalidades de trabalho, como o voluntário e o doméstico. Desse modo, este é apenas um passo inicial, havendo ainda bastante espaço para a implementação de investigações futuras.

\section{Referências bibliográficas}

Ali, A. J.; FAlCone, T.; Azim, A. A. "Work ethic in the USA and Canada". Journal of Management Development, vol. 14, no 6, p. 26-34, ago. 1995.

Allan, B. A.; AUtin, K. L.; Duffy, R. D. "Examining social class and work meaning within the psychology of working framework". Journal of Career Assessment, vol. 22, no 4, p. 543-561, 11 nov. 2014.

ALonso, F. S. A., et al. "Trabalho e aprendizagem: as perspectivas de futuro profissional de jovens aprendizes na cidade de Três Rios, RJ". Revista de Administração do Unifatea - RAF, vol. 13, n० 13, p. $64-84,2016$.

ANTUNES, R. Os sentidos do trabalho: ensaios sobre a afirmação e a negação do trabalho. $2^{a}$ ed. São Paulo: Boitempo Editorial, 2009.

ARAÚjo, R. R.; SACHUK, M. I. "Os sentidos do trabalho e suas implicações na formação dos indivíduos inseridos nas organizações contemporâneas". Revista de Gestão USP, vol. 14, no 1, p. 53-66, 2007. 
ARDICHVILI, A.; KUCHINKE, K. P. "International perspectives on the meanings of work and working: current research and theory". Advances in Developing Human Resources, vol. 11, no 2, p. 155-167, 24 abr. 2009.

ARSLAN, M. "The work ethic values of protestant British, catholic Irish and Muslim Turkish managers". Journal of Business Ethics, vol. 31, no 4, p. 321-339, 2001.

Bastos, A. V. B.; Pinho, A. P. M.; CostA, C. A. "Significado do trabalho: um estudo entre trabalhadores inseridos em organizações formais". RAE - Revista de Administração de Empresas, vol. 35, no 6, p. 20-29, 1995.

BENDASSOLLI, P. F. Trabalho e identidade em tempos sombrios: insegurança ontológica na experiência atual com o trabalho. Aparecida, São Paulo: Ideias e Letras, 2007.

Bendassolli, P. F.; Borges-Andrade, J. E. "Significado do trabalho nas indústrias criativas". RAE, vol. 51, no 2, p. 143-159, 2011.

Bitencourt, B. M., et al. "Sentidos do trabalho para jovens de um empreendimento solidário e para trainees". Gerais: Revista Interinstitucional de Psicologia, vol. 7, no 2, p. 142-155, 2014.

Bizerra, F. A.; SouzA, R. M. "A 'sociedade de informação' e a centralidade do trabalho: uma relação polêmica". Argumentum, vol. 6, no 1, p. 253-270, 2014.

Blau, P.; Duncan, O. The American occupational structure. New York: The Free Press, 1967.

BLUSTEIN, D. L., et al. "Voices of the forgotten half: the role of social class in the school-to-work transition". Journal of Counseling Psychology, vol. 49, no 3, p. 311-323, 2002.

BoRGES, L. D. O. "A estrutura fatorial dos atributos valorativos e descritivos do trabalho: um estudo empírico de aperfeiçoamento e validação de um questionário". Estudos de Psicologia, vol. 4, no 1, p. 107-139, 1999.

Borges, L. D. O.; BARRos, S. C. Inventário de significado do trabalho para trabalhadores de baixa instrução. In: Puente-PAlÁcios, K.; PeiXoto, A. L. A. (eds.). Ferramentas de diagnóstico para organizações e trabalho: um olhar a partir da psicologia. Porto Alegre: Artmed, p. 232-253, 2015.

CARDoso, L. A. "A centralidade da categoria trabalho: uma análise crítica do debate sociológico contemporâneo". Confluências - Revista Interdisciplinar de Sociologia e Direito, vol. 10, no 1, p. 11$41,2008$.

CARdoso, A. A., et al. "Protestantismo, motivação e mobilidade: dois estudos sobre religião e comportamento econômico". Teoria \& Sociedade, vol. 17, no 2, p. 216-239, 2009.

CARTWRIGHT, S.; HOLMES, N. "The meaning of work: the challenge of regaining employee engagement and reducing cynicism". Human Resource Management Review, vol. 16, n 2, p. 199-208, 2006.

CASTEL, R. Las metamorfosis de la cuestión social: una crónica del salariado. Buenos Aires: Editorial Paidós, 1997.

Castells, M. A sociedade em rede. 6a ed., vol. 1. São Paulo: Paz e Terra, 2011.

CAStRo, H. C. O.; RAnincheSki, S.; CAPIStRAno, D. "O conteúdo da globalização para os latinoamericanos: uma análise a partir da Pesquisa Mundial de Valores - WVS". Temas y Debates, vol. 19, no 29, p. 53-76, 2015.

CODA, R.; FONSECA, G. F. "Em busca do significado do trabalho: relato de um estudo qualitativo entre executivos". Revista Brasileira de Gestão de Negócios, vol. 6, no 14, p. 7-18, 2004. 
DAHRENDORF, R. "Is the work society running out of work?". Omega, vol. 8, no 3, p. 281-285, jan. 1980.

DAVIDSON, J. C.; CADDELL, D. P. "Religion and the meaning of work". Journal for the Scientific Study of Religion, vol. 33, n 2, p. 135, 1994.

De La Garza, E.; Hernández, J. M. Fin del trabajo o trabajo sin fin. In: De La Garza Toledo, e. (coord.). Tratado latinoamericano de sociología del trabajo. Ciudad de México: Fondo de Cultura Econômica, p. 755-774, 2000.

DEN DULK, L., et al. "National context in work-life research: a multi-level cross-national analysis of the adoption of workplace work-life arrangements in Europe". European Management Journal, vol. 31, no $^{\circ}$, p. 478-494, out. 2013.

DUBIN, R. "Industrial workers' worlds: a study of the 'central life interests' of industrial workers". Social Problems, vol. 3, n 3, p. 131-142, 1956.

DuFFY, R. D., et al. "Calling and life satisfaction: it's not about having it, it's about living it". Journal of Counseling Psychology, vol. 60, no 1, p. 42-52, 2013.

ELIAS, N. A sociedade dos indivíduos. Rio de Janeiro: Jorge Zahar, 1994.

GEORGES, I. Entre discriminação e reconhecimento: as trabalhadoras domésticas de São Paulo. In: Cabanes, R.; Georges, I.; Rizek, C. S. (eds.). Saídas de emergência. São Paulo: Boitempo, 2011.

GESER, H. "Work values and Christian religiosity. An ambiguous multidimensional relationship". Journal of Religion \& Society, vol. 11, p. 1-36, 2009.

GoRz, A. Farewell to the working class: an essay on post-industrial socialism. London: Pluto Press, 1982.

GoULART, P. M. "O significado do trabalho: delimitações teóricas (1955-2006)". Cadernos de Psicologia Social e do Trabalho, vol. 12, no 1, p. 47-55, 2009.

HAIR, J. F. J., et al. Análise multivariada de dados. 6a ed. Porto Alegre: Bookman, 2009.

HAJDU, G.; SIK, E. "Age, period, and cohort differences in work centrality and work values". Societies, vol. 8, n $^{\circ} 1$, p. 11,12 fev. 2018.

HARPAZ, I. "Cross-national comparison of religious conviction and the meaning of work". CrossCultural Research, vol. 32, n² 2, p. 143-170, 1998.

HARPAZ, I.; FU, X. "The structure of the meaning of work: a relative stability amidst change". Human Relations, vol. 55, p. 639-668, 2002.

HARPAZ, I.; MeShoulam, I. "Differences in the meaning of work in Israel: workers in high-tech versus traditional work industries". The Journal of High Technology Management Research, vol. 15, n० 2, p. 163-182, ago. 2004.

Hirata, H. "Gênero, patriarcado, trabalho e classe". Trabalho Necessário, vol. 16, no 29, p. 14-27, 2018.

HIRSCHFELD, R. R.; FEILD, H. S. "Work centrality and work alienation: distinct aspects of a general commitment to work". Journal of Organizational Behavior, vol. 21, p. 789-800, 2000.

HirviLAmmi, T., et al. "Reflecting on work values with young unemployed adults in Finland". Nordic Journal of Working Life Studies, vol. 9, no 2, p. 87-104, 2019. 
INGLEHART, R. "Changing values among Western publics from 1970 to 2006". West European Politics, vol. 31, no 1-2, p. 130-146, 2008.

INGLEHART, R. Cultural evolution: people's motivations are changing, and reshaping the world. New York: Cambridge University Press, 2018.

INGLEHART, R.; Welzel, C. Modernization, culture change, and democracy: the human development sequence. New York: Cambridge University Press, 2005.

INGLEHART, R., et al. World values surveys and European values surveys, 1981-1984, 1990-1993, and 1995-1997. Ann Arbor, Michigan: ICPSR Inter-University Consortium for Political and Social Research, 2000.

World values survey: Round five - Country-pooled datafile. Madrid, Spain; Vienna, Austria: JD Systems Institute \& WVSA Secretariat, 2018.

KAPLAN, H. R.; TAUSKY, C. "The meaning of work among the hard-core unemployed". The Pacific Sociological Review, vol. 17, no 2, p. 185-198, 1974.

KLONOSKI, R. "Assessing lower and higher order needs: a cross-cultural comparative study". British Journal of Economics, Management \& Trade, vol. 4, no 2, p. 173-182, 10 jan. 2014.

KovÁcS, I. "Novas formas de organização do trabalho e autonomia no trabalho". Sociologia, Problemas e Práticas, vol. 52, p. 41-65, 2006.

KUBo, S. H.; GouvÊA, M. A. "Análise de fatores associados ao significado do trabalho". Revista de Administração, vol. 47, no 4, p. 540-554, 2012.

Kubo, S. H.; GouvÊA, M. A.; MANTOVANI, D. M. N. "Dimensões do significado do trabalho e suas relações". Pretexto, vol. 14, no 3, p. 28-49, 2013.

LU, Q.; HuAnG, X.; Bond, M. H. "Culture and the working life". Journal of Cross-Cultural Psychology, vol. 47, no 2, p. 277-293, 20 fev. 2016.

MADALOZZO, R.; MARTINS, S. R.; SHIRATORI, L. "Participação no mercado de trabalho e no trabalho doméstico: homens e mulheres têm condições iguais?". Estudos Feministas, vol. 18, no 2, p. 547$566,2010$.

MARôco, J. Análise de equações estruturais: fundamentos teóricos, software \& aplicações. $2^{a}$ ed. Pêro Pinheiro: ReportNumber, Lda, 2014.

MATTOS, E. D.; ChAVES, A. M. "As representações sociais do trabalho entre adolescentes aprendizes: um estudo piloto". Revista Brasileira de Crescimento e Desenvolvimento Humano, vol. 16, no 3, p. 66-75, 2006.

MÉDA, D. Le travail: une valeur en voie de disparition? Paris: Flammarion, 2010.

MÉdA, D.; Vendramin, P. Reinventing work in Europe. France: Palgrave Macmilan, 2013.

MejÍA ReYES, C. "La centralidad del trabajo y su relación con variables macroeconómicas. Una lectura del caso mexicano en comparativa". Investigación y Ciencia, no 71, p. 68-76, 2017.

Mejía Reyes, C.; Martín Artiles, A. "La centralidad del trabajo en Estados Unidos de América. Una exploración transversal: 1995-2014". Sociedad y Economía, vol. 34, p. 185-209, 2018.

Morin, E.; Tonelli, M. J.; Pliopas, A. L. V. "O trabalho e seus sentidos". Psicologia \& Sociedade, vol. $19, n^{\circ} 1$, p. $47-56,2007$. 
MORSE, N. C.; WeISS, R. S. "The function and meaning of work and the job". American Sociological Review, vol. 20, no 2, p. 191-198, 1955.

MOW, International Research Center Team. The meaning of working. London: Academic Press, 1987.

Navarro, V. L.; PAdilha, V. "Dilemas do trabalho no capitalismo contemporâneo". Psicologia \& Sociedade, vol. 19, no 1, p. 14-20, 2007.

NEVES, J. A. B. Modelo de equações estruturais: uma introdução aplicada. Brasília: Enap, 2018.

OffE, C. "Trabalho: a categoria-chave da sociologia?". RBCS, vol. 4, nº 10, p. 1-34, 1989.

OGUEGBE, T. M., et al. "Role of self-efficacy and sex on work centrality among workers". International Journal of Humanities and Social Science, vol. 4, nº 5, p. 297-302, 2014.

Oliveira, S. R. D.; Piccinini, V. C. A constituição do trabalho na sociedade moderna. In: Piccinini, V. C.; ALmeIDA, M. L. D.; OLIVEIRA, S. R. D. (eds.). Sociologia e administração: relações sociais nas organizações. p. 203-217. [s.I.] Elsevier, 2011.

PARboteEAH, K. P.; CULlen, J. B. "Social institutions and work centrality: explorations beyond national culture". Organization Science, vol. 14, n 2, p. 137-148, 2003.

Parboteeah, K. P.; Hoegl, M.; Cullen, J. "Religious dimensions and work obligation: a country institutional profile model". Human Relations, vol. 62, nº 1, p. 119-148, jan. 2009.

Pérezgonzález, J. D.; VileLA, L. D. La centralidad del trabajo. Dublin: Lulu Inc, 2005.

PYÖRIÄ, P., et al. "The millennial generation: a new breed of labour?". SAGE Open, p. 1-14, 2017.

Queiroz, V. D. S.; ARAgón, J. A. O. "Alocação de tempo em trabalho pelas mulheres brasileiras". Estudos Econômicos, São Paulo, vol. 45, no 4, p. 787-819, 2015.

Rodrigues, A. L.; BARRICHello, A.; MORIN, E. M. "Os sentidos do trabalho para profissionais de enfermagem: um estudo multimétodos". RAE, vol. 56, no 2, p. 192-208, abr. 2016.

RodRIGUeS, A. L., et al. "Meaning of work: challenges for the XXI century". RAM, vol. 19, p. 2-8, 2018.

Rosso, B. D.; DEKAS, K. H.; WRZESNIEWSKI, A. "On the meaning of work: a theoretical integration and review". Research in Organizational Behavior, vol. 30, p. 91-127, jan. 2010.

Ruiz-QuinTANilLA, S. A. "Introduction: the meaning of work". European Work and Organizational Psychologist, vol. 1, no 2-3, p. 81-89, abr. 1991.

Ruiz-Quintanilla, S. A.; CLAES, R. Mow research programs. In: KaTZ, J. A. (ed.). Databases for the study of entrepreneurship. New York: Elsevier Science, p. 335-391, 2000.

RUIZ-QUinTANILLA, S. A.; WiLPERT, B. "Are work meanings changing?". European Work and Organizational Psychologist, vol. 1, no 2-3, p. 91-109, 1991.

SABOYA, M. C. L. "Socialização e qualificação para o trabalho: construção de identidades". Educação, Gestão e Sociedade, Revista da Faculdade Eça de Queirós, vol. 4, no 18, p. 1-16, 2015.

SALINAS-JimÉnEZ, M., et al. "Income, motivation, and satisfaction with life: an empirical analysis". Journal of Happiness Studies, vol. 11, no 6, p. 779-793, 9 dez. 2010.

SAntos, T. A. "Os sentidos do trabalho para os agentes penitenciários: uma análise na cadeia pública de Salvador". Revista Formadores: Vivências e Estudos, vol. 7, n² 2, p. 19-34, 2014. 
STEENKAMP, P. L. "Protestant ethic: contributing towards a meaningful workplace". HTS Teologiese Studies/Theological Studies, vol. 69, no 1, p. 1-11, 14 jan. 2013.

SteYN, C.; KotzÉ, H. "Work values and transformation: the South African case, 1990-2001". Society in Transition, vol. 35, no 1, p. 145-164, jan. 2004.

Tolfo, S. D. R.; Piccinini, V. C. "Sentidos e significados do trabalho: explorando conceitos, variáveis e estudos empíricos brasileiros". Psicologia \& Sociedade, vol. 19, p. 38-46, 2007.

Tolfo, S. D. R., et al. "Sentidos y significados del trabajo: un análisis con base en diferentes perspectivas teóricas y epistemológicas en psicologia". Universitas Psychologica, vol. 10, n 1, p. 175-188, 2011.

TORGLER, B. "Work values in western and eastern Europe: paper 645". Fondazione Eni Enrico Mattei. Working Papers, [s.n.], 2012.

VECCHIO, R. P. "The function and meaning of work and the job: Morse and Weiss (1955) revisited". Academy of Management Journal, vol. 23, n² 2, p. 361-367, 1980.

VILAS BOAS, A. A.; MORIN, E. M. "Sentido do trabalho e fatores de qualidade de vida no trabalho para professores de universidades públicas do Brasil e do Canadá". In: XXXVIII Encontro da ANPAD EnANPAD, Rio de Janeiro, Brasil, 2014.

. "Sentido do trabalho e orientação para o trabalho: um estudo em universidades públicas de Minas Gerais e do Quebec". Gestão Universitária na América Latina - GUAL, vol. 8, no 4, p. 117, 2015.

WARR, P. "Work values: some demographic and cultural correlates". Journal of Occupational and Organizational Psychology, vol. 81, no 4, p. 751-775, dez. 2008.

Weber, M. A ética protestante e o "espírito" do capitalismo. São Paulo: Companhia das Letras, 2004.

YEGANEH, H. "Cultural modernization and work-related values and attitudes: an application of Inglehart's theory". International Journal of Development Issues, vol. 16, no 2, p. 130-146, 2017.

ZuBieTA, E. La socialización para el trabajo. In: Guzmán, M. L. J.; Boso, R. (eds.). Juventud precarizada: de la formación al trabajo, una transición riesgosa. Cuernavaca: UAM, Centro Regional de Investigaciones Multidisciplinarias, p. 265-293, 2012.

ZUBIETA, E., et al. "Concepciones y creencias sobre el trabajo. Estudio descriptivo de algunas fuentes de variación en una muestra laboralmente activa". Anuario de investigaciones, vol. XV, p. 35-50, 2008.

\begin{abstract}
The influence of demographic and structural factors on the meanings of work among Brazilians: evidence from the World Values Survey

Work underwent transformations that changed the values and determinants of their meanings, putting its centrality in check. This research investigates the meanings of work among Brazilians, as well as the influence of demographic and structural elements on this attribution. The meanings of work refer to individual interpretation, influenced by the social context, about work and what it represents. World Values Survey Brazilian's sample was used. The influence of socioeconomic and structural characteristics was analyzed via structural equation modeling. The model was well adjusted, having a coefficient of determination of .951. Descriptive results indicated high valuation of work and strong perception of it as a social obligation. The SEM results indicated that men attribute higher meaning to work compared to women and that increasing age influences the attribution of meaning to work. Activities with creativity, intellectuality and independence
\end{abstract}


have indirect (via NSE) and negative influence on the perception of work meanings. Analyzes prioritized the articulation between social and economic aspects with the process of meaning of work, a perspective little explored in the Brazilian's scientific production, but fundamental for a broader understanding of the phenomenon, especially in stratified societies such as Brazil.

Keywords: meanings of work; Brazilians; influence factors; World Values Survey

\section{Resumen}

La influencia de los factores demográficos y estructurales en los significados del trabajo entre los brasileños: evidencias de la Encuesta Mundial de Valores

El trabajo experimentó transformaciones que cambiaron los valores y determinantes de sus significados, cuestionando su centralidad. Esta investigación analiza los significados del trabajo entre los brasileños, así como la influencia de los elementos demográficos y estructurales en esta atribución. Los significados del trabajo se refieren a la interpretación individual, influenciada por el contexto social, el trabajo y lo que representa. Se utilizó la muestra brasileña de la Encuesta Mundial de Valores. La influencia de las características socioeconómicas y estructurales se analizó mediante modelos de ecuaciones estructurales. El modelo estaba bien ajustado, con un coeficiente de determinación de .951. Los resultados descriptivos indicaron una alta valoración del trabajo y una fuerte percepción de este como una obligación social. Los resultados de MME indicaron que los hombres atribuyen mayor significado al trabajo en comparación con las mujeres y que el aumento de la edad influye en Iva atribución de significado al trabajo. La creatividad, la intelectualidad y la independencia en las actividades realizadas tienen una influencia indirecta (a través de NSE) y negativa en la percepción de los significados del trabajo. Los análisis priorizaron la articulación entre los aspectos sociales y económicos con el proceso de significado del trabajo, una perspectiva poco explorada en la producción científica brasileña, pero fundamental para que el fenómeno se entienda de manera más amplia, especialmente en sociedades estratificadas, como Brasil.

Palabras clave: significados del trabajo; brasileños; factores de influencia; encuesta mundial de valores

\section{Résumé}

L'influence des facteurs démographiques et structurels sur la signification du travail chez les Brésiliens: données tirées du World Values Survey

Le travail a subi des transformations qui ont changé les valeurs et les déterminants de leurs significations, en mettant en échec leur centralité. Cette recherche examine la signification du travail chez les Brésiliens, ainsi que l'influence des éléments démographiques et structurels sur cette attribution. Les significations du travail renvoient à une interprétation individuelle, influencée par le contexte social, le travail et ce qu'il représente. L'échantillon brésilien du World Values Survey a été utilisé. L'influence des caractéristiques socioéconomiques et structurelles a été analysée via modélisation par équation structurelle. Le modèle a été bien ajusté $(C D=.951)$. Les résultats descriptifs indiquaient une élevée valorisation du travail et forte perception de celui-ci en tant qu'obligation sociale. Les résultats du MME indiquent que les hommes attribuent plus de sens au travail que les femmes et que l'âge augmente l'influence du sens du travail. La créativité, l'intellectualité et l'indépendance des activités exercées ont une influence indirecte (à travers de NSE) et négative sur la perception des significations du travail. Les analyses ont priorisé l'articulation entre les aspects sociaux et économiques et le processus de signification du travail, une perspective peu explorée dans la production scientifique brésilienne, mais fondamentale pour une compréhension du phénomène, en particulier dans des sociétés stratifiées telles que le Brésil.

Mots-clés: significations du travail; Les brésiliens; facteurs d'influence; enquête sur les valeurs mondiales

Artigo submetido à publicação em 24 de setembro de 2019. Versão final aprovada em 3 de maio de 2021.

Opinião Pública adota a licença Creative Commons CC-BY. 